\title{
Magnetic Janus Particles for Static and Dynamic (Bio)Sensing
}

\author{
Susana Campuzano $\unrhd$, Maria Gamella, Verónica Serafín, María Pedrero $₫$, Paloma Yáñez-Sedeño \\ and José Manuel Pingarrón * $\mathbb{D}$ \\ Departamento de Química Analítica, Facultad de CC. Químicas, Universidad Complutense de Madrid, \\ E-28040 Madrid, Spain \\ * Correspondence: pingarro@quim.ucm.es; Tel.: +34-913944315
}

Received: 29 July 2019; Accepted: 19 August 2019; Published: 22 August 2019

check for updates

\begin{abstract}
Magnetic Janus particles bring together the ability of Janus particles to perform two different functions at the same time in a single particle with magnetic properties enabling their remote manipulation, which allows headed movement and orientation. This article reviews the preparation procedures and applications in the (bio)sensing field of static and self-propelled magnetic Janus particles. The main progress in the fabrication procedures and the applicability of these particles are critically discussed, also giving some clues on challenges to be dealt with and future prospects. The promising characteristics of magnetic Janus particles in the (bio)sensing field, providing increased kinetics and sensitivity and decreased times of analysis derived from the use of external magnetic fields in their manipulation, allows foreseeing their great and exciting potential in the medical and environmental remediation fields.
\end{abstract}

Keywords: magnetic Janus particles; (bio)sensing; static; self-propelled

\section{Introduction}

In 1989, Casagrande et al. [1] described the preparation of spherical particles from commercial glass spheres with diameters in the 50-90 $\mu \mathrm{m}$ range bearing half-hydrophilic half-hydrophobic surfaces. These particles were coined as "Janus beads" after the Roman God Janus depicted with twin faces, one looking to the future and the other to the past [2]. Unlike conventional particles, two-faced Janus particles provide asymmetry and directionality and can combine different or even incompatible properties within a single particle [3,4]. The surface anisotropy of these particles spatially decouples analytical functions (e.g., targeting and sensing) and allows spatial-selective bioconjugation that would otherwise be difficult to combine within the uniform composition or heterogeneous nanoparticles. Therefore, Janus nanoparticles have properties and functions, such as dual-targeting [5] and molecular sensing, which are incompatible when combined in a single structural unit or in heterogeneous "not Janus" nanoparticles, thus, opening opportunities for the construction of truly multifunctional entities [6,7]. Moreover, the asymmetry of the Janus particles surface (ratio of surface area devoted to different surface types on the two sides of the particle) can be varied at will depending on the particular applications without altering, interfering or losing the intrinsic properties of both faces, which makes them a unique category of materials in contrast to other particles. Since their development, these particles and their synthetic methods have evolved rapidly as they have been adapted to different applications and profited of the important advances in micro- and nano-manipulation systems and fabrication procedures. This evolution may include the introduction of a magnetic component (i.e., iron, nickel, $\mathrm{Fe}-\mathrm{Ti}, \mathrm{CoNi}$ ) that allows driving them by means of a magnetic field towards different places in the human body where therapeutic drugs are released (i.e., drug delivery), to trap undesired entities (i.e., microorganisms), to be used for magnetic resonance imaging, separation of biological 
molecules or (bio)chemical sensing [8] or to perform many other applications as magnetically triggered devices in the biomedical area [9]. This displacement based on the magnetic field is useful for in vivo biomedical applications because these nano-systems can be precisely controlled by magnetic forces while their speed remains constant regardless of the medium through which they move. Moreover, these biocompatible, non-toxic particles are capable of travelling along the human body without harming cells and tissues. Therefore, a variety of magnetic micro- and nano-systems have already been reported in the literature for several biomedical applications with no adverse interactions with human tissues no matter the biological fluid conditions [10].

The great importance, applicability and future prospects that these devices promise have been already reviewed in articles focused on self-propelled affinity biosensors [11], biosensing with different magnetic particle labels, including Janus particles [12], Janus particles for biological imaging and sensing [7], or for biosensing [4], magnetically driven micro- and nano-robots [10], micro-/nano-robots for biomedicine [13], nano-/micro-systems for delivery and (bio)sensing at the cellular level [8], targeting and isolation of cancer cells [14], or the use of micromotors for biosensing applications [15]. Considering that the application of magnetic Janus particles in the (bio)sensing field is gaining importance rapidly, this review article is focused to the recent developments and applications of these particles both as static and dynamic (bio)sensing systems. Outstanding developments, current trends, challenges and prospects in this exciting field are highlighted and discussed.

\section{Synthesis of Magnetic Janus Particles}

The methods for the synthesis of magnetic Janus particles are diverse and difficult to classify [16]. A variety of synthetic strategies has been reported in the literature which, at least in part, can be classified as belonging to one of the following categories: (a) Masking or template; (b) direct deposition; (c) phase separation; and (d) self-assembly. An optional preparation method also includes bubble-templated assembly [17]. In the masking approach, the particles, trapped at the interface between two phases, are modified only on one side. Similarly, the template methods involve the use of sacrificial material to cover a part of the particle, while the other is modified [18]. In a direct deposition, the functionalizing material is driven only to the desired area of the particle. Fabrication methods based on phase separation require the use of two immiscible precursors and the existence of an interface. Microfluidics or emulsification with two immiscible fluids, where a liquid-liquid interface is formed, are alternatives explored for the preparation of anisotropic magnetic particles [19-22]. Regarding solid-liquid interfaces, the solid particle is usually employed as a nucleation site for the condensation of the liquid. Self-assembly methods are based on the spontaneous assembling of particles which act as building blocks for simple structures by entropy minimization [23]. Assembling may be directed by application of magnetic or electric fields and depends largely on the properties of the surrounding solution. In this section, some recent methods reported for the synthesis of magnetic Janus particles noted for their relevance and the practical utility of the resulting materials are reviewed.

$\mathrm{Fe}_{3} \mathrm{O}_{4}$ amphiphilic Janus nanoparticles ( $\mathrm{Fe}_{3} \mathrm{O}_{4} @ \mathrm{AJNPs}$ ) bearing $\beta$-cyclodextrin $(\beta-\mathrm{CD})$ and aminopyridine (APD) functionalized polymethyl methacrylate (PGMA) were prepared to construct $\mathrm{pH}$-stimuli responsive co-assemblies through host-guest interactions between $\beta$-CD and APD [24]. As it is shown in Figure 1, hydrophilic superparamagnetic $\mathrm{Fe}_{3} \mathrm{O}_{4}$ nanoparticles (NPs) were used to obtain $\mathrm{Fe}_{3} \mathrm{O}_{4}$ wax microspheres employing Pickering emulsion by stirring in paraffin wax and dispersion in dimethylformamide (DMF). A further condensation reaction occurred between the particles and polyethylene glycol (PEG) to yield PEG- $\mathrm{Fe}_{3} \mathrm{O}_{4} /$ wax composite microspheres which were washed with chloroform to dissolve the wax. PEG-Fe $\mathrm{O}_{4}-\mathrm{Br}$ NPs were obtained by reaction with bromoacetic acid, and the ARGET ATRP technique (activators regenerated by the electron transfer for atom transfer radical polymerization) [25] was applied to graft polymethyl methacrylate-methacrylate (PMMA-MA) brushes onto the opposite hemisphere of PEG-Fe $\mathrm{O}_{4}-\mathrm{Br} \mathrm{NPs}$, thus, obtaining the amphiphilic Janus PEG-Fe ${ }_{3} \mathrm{O}_{4}$-PMMA-MA. Finally, hydroxypropyl- $\beta-\mathrm{CD}$ reacted with $\mathrm{PEG}-\mathrm{Fe}_{3} \mathrm{O}_{4}-\mathrm{PMMA-MA}$ through the condensation among the carboxyl groups in PMMA-MA and the hydroxyls in CD to obtain 
the functionalized amphiphilic Janus PEG- $\mathrm{Fe}_{3} \mathrm{O}_{4}$-PMMA-MA (CD), which were also named as $\mathrm{Fe}_{3} \mathrm{O}_{4} @ \mathrm{AJNPs}$.

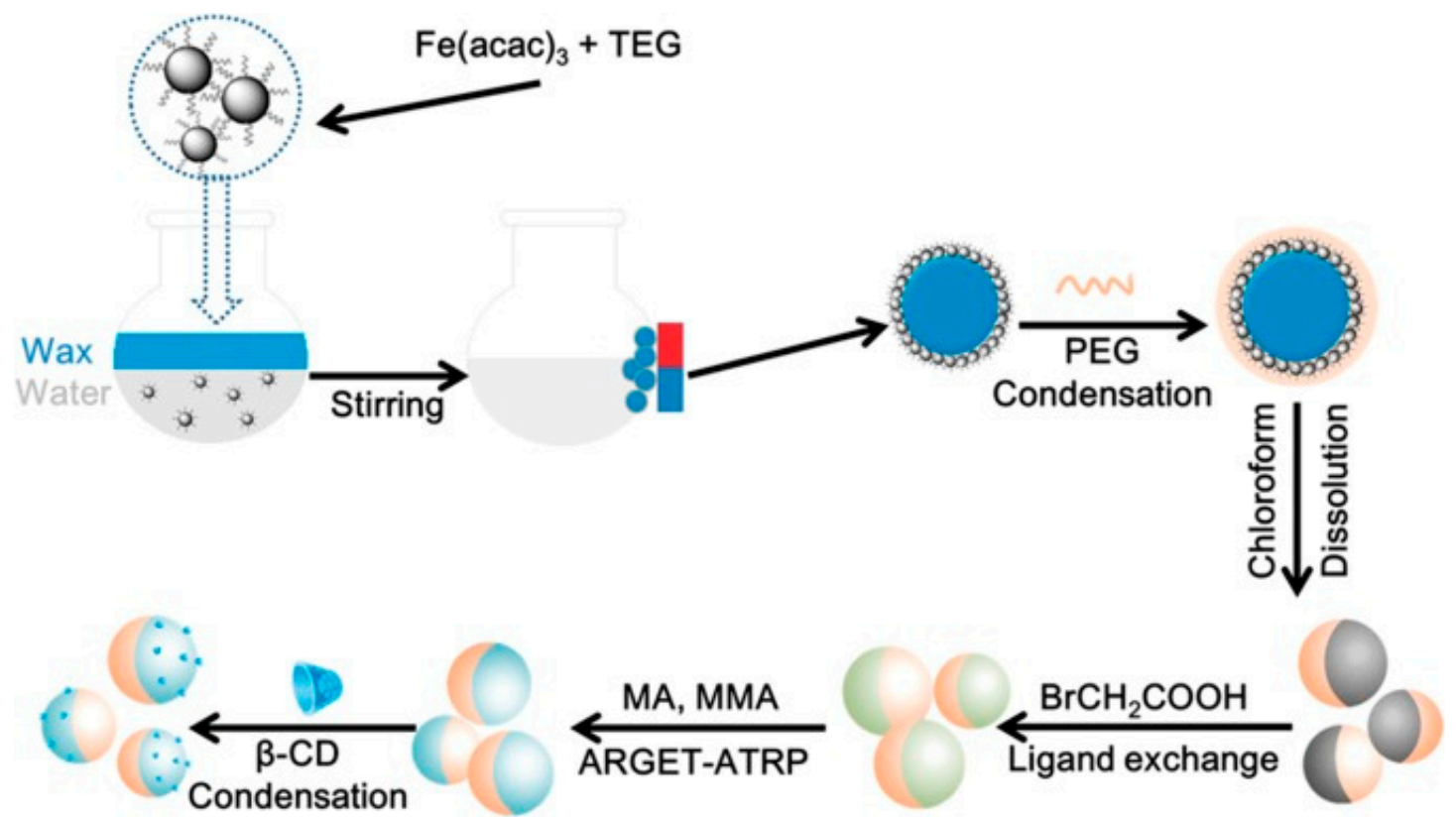

Figure 1. Schematic display of the method for the synthesis of $\mathrm{Fe}_{3} \mathrm{O}_{4} @ \mathrm{AJNPs}$. Reproduced from Reference [24] with permission.

Pickering emulsion was employed recently by Shaghaghi et al. [26] for the preparation of various types of Janus superparamagnetic iron oxide nanoparticles (SPIONs) decorated with folic acid (FA) and doxorubicin (DOX) with the aim of accumulating target cancerous cells through the FA ligands and deliver chemotherapy drugs. SPIONs were firstly masked and immobilized in paraffin wax particles for the subsequent synthesis of drug-conjugated Janus NPs (Figure 2). The waxed magnetic cores were half-coated by (3-mercaptopropyl) triethoxysilane (MPTES), and then dewaxed in solvents for a further anchoring of azide-3-aminopropyl-triethoxysilane $\left(\mathrm{N}_{3}\right.$-APTES) on the free side of the particle. Then, mono(acryloyl)-star-poly-(ethylene glycol) (Acl-sPEG) was conjugated to the core via thiolene click reaction in the presence of azobisisobutyronitrile (AIBN). Thereafter, N-hydroxysuccinimide (NHS)-ester of folic acid was grafted to sPEG to obtain SPION-sPEG-FA. The preparation of DOX-PCL-SPION (PCL = poly ( $\varepsilon$-caprolactone) $)$ involved grafting of DOX-PCL-yne to the particle via azid-yne click reaction in the presence of $\mathrm{N}, \mathrm{N}, \mathrm{N}^{\prime}, \mathrm{N}^{\prime \prime}, \mathrm{N}^{\prime \prime}$-pentamethyl diethylene-triamine (PMDETA). 


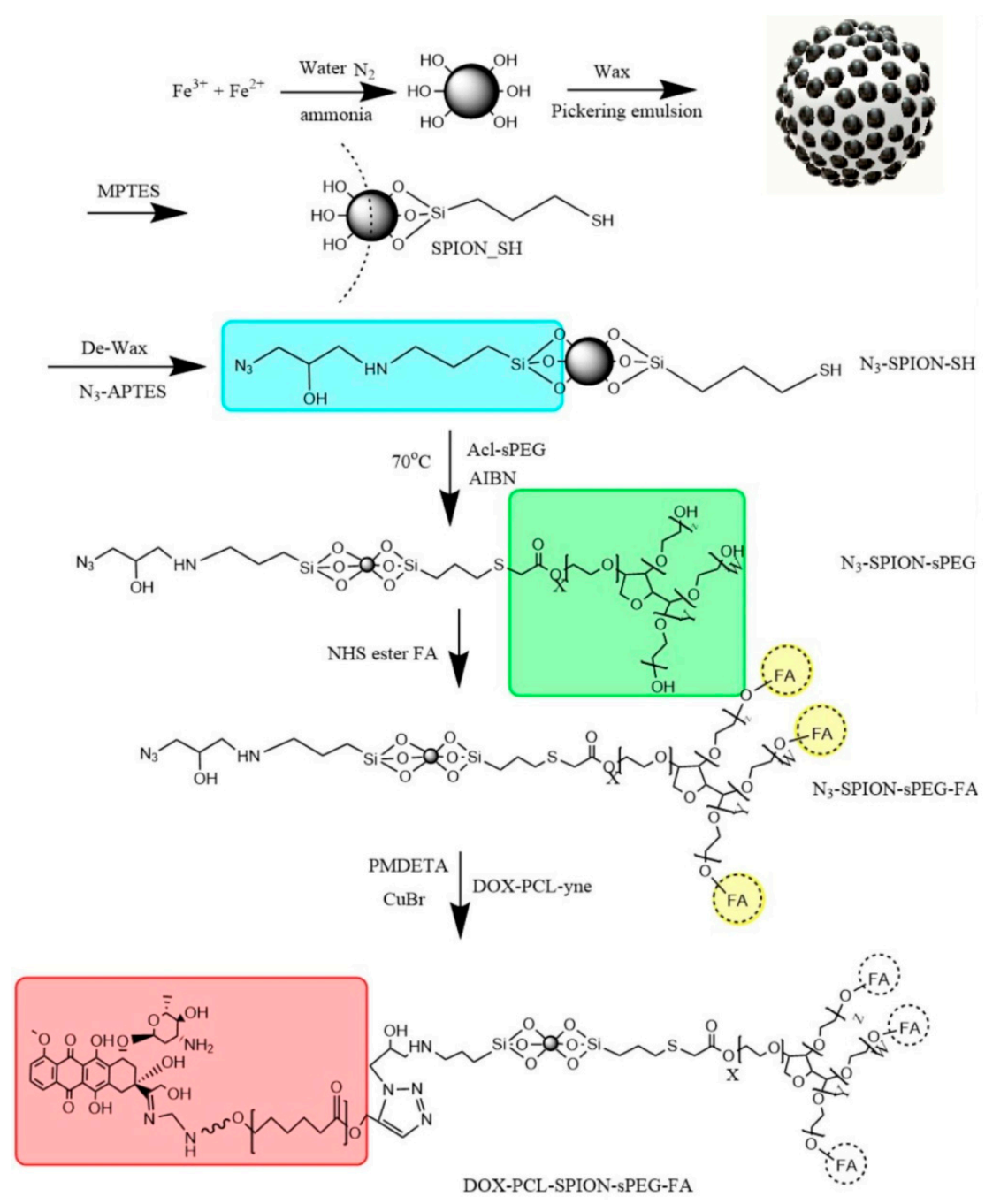

Figure 2. Scheme of the steps involved in the synthesis of drug-conjugated Janus nanoparticles (NPs). Reprinted from Reference [26] with permission.

$\mathrm{Fe}_{3} \mathrm{O}_{4}$-metal Janus nanoparticles have been used for a variety of interesting applications. An illustrative example is the recent synthesis of $\mathrm{Fe}_{3} \mathrm{O}_{4}$ - $\mathrm{Ag}$ nanocomposites through a two-step solvothermal method. Once $\mathrm{Fe}_{3} \mathrm{O}_{4}$ particles were prepared, they were added to an $\mathrm{AgNO}_{3}$ solution in acetic acid/acetate ethanolic mixture under ultrasonic dispersion followed by heating in an autoclave [27]. The prepared material exhibited not only magnetic properties, but also surface-enhanced Raman scattering (SERS) effect and was used as a substrate to detect adsorbed molecules on surfaces. Another interesting work implies the synthesis of Janus bifunctional composite $\mathrm{Au}-\mathrm{Fe}_{3} \mathrm{O}_{4} \mathrm{NPs}$ by means of a microwave heating. Two types of amphiphilic Janus $\mathrm{Au}-\mathrm{Fe}_{3} \mathrm{O}_{4} \mathrm{NPs}$ were prepared by coating with bi-compartment polymer brushes exhibiting opposite amphiphilic properties on $\mathrm{Au}$ and $\mathrm{Fe}_{3} \mathrm{O}_{4}$ surfaces by the ligand exchange method. Specifically, Au@PEGFe ${ }_{3} \mathrm{O}_{4} @$ polystyrene (PS) Janus NPs, with PEG coating on the Au surface, and PS coating on the $\mathrm{Fe}_{3} \mathrm{O}_{4}$ surface were obtained by adding a mixture of thiolated polyethylene glycol (PEG-SH) and phosphonated polystyrene (PS-P) to the $\mathrm{Au}-\mathrm{Fe}_{3} \mathrm{O}_{4} \mathrm{NPs}$. In addition, $\mathrm{Au} @ \mathrm{PSFe}_{3} \mathrm{O}_{4} @ \mathrm{PEG}$ Janus NPs, with PS grafting on $\mathrm{Au}$ and PEG on $\mathrm{Fe}_{3} \mathrm{O}_{4}$, were prepared by adding a PEG-P and PS-SH mixture to Janus NPs. Double-layered plasmonic-magnetic vesicles were prepared from the synthesized NPs (Figure 3). Moreover, the amphiphilic distribution of the polymer grafts on the Janus $\mathrm{Au}-\mathrm{Fe}_{3} \mathrm{O}_{4}$ surface, allows easily reversing the positions of the $\mathrm{Au}$ and $\mathrm{Fe}_{3} \mathrm{O}_{4}$ in the vesicular shell by changing the amphiphilic properties of the polymer brushes coated on their surface, with Au extended mostly to the outside and $\mathrm{Fe}_{3} \mathrm{O}_{4}$ localized inside the shell, or 
conversely. The resultant vesicles exhibited greatly enhanced optical and magnetic properties taking advantage from both the interparticle plasmonic coupling of the Au NPs and the magnetic interaction of the $\mathrm{Fe}_{3} \mathrm{O}_{4}$ localized in the doubled vesicular shell [28].

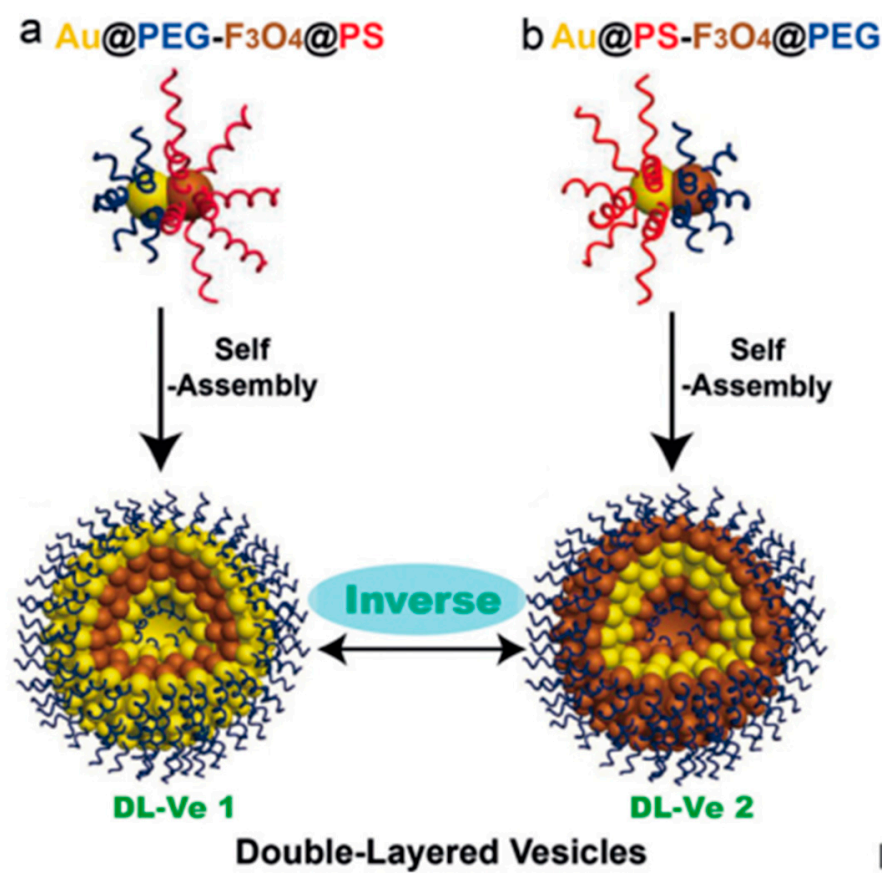

Figure 3. Schematic illustration of the Janus $\mathrm{Au}-\mathrm{Fe}_{3} \mathrm{O}_{4} \mathrm{NPs}$ grafted with hydrophilic polyethylene glycol (PEG) on $\mathrm{Au}$ and hydrophobic PS on $\mathrm{Fe}_{3} \mathrm{O}_{4}(\mathbf{a})$, and with PS on $\mathrm{Au}$ and PEG on $\mathrm{Fe}_{3} \mathrm{O}_{4}(\mathbf{b})$, and the hierarchical self-assembly of the resulting Janus amphiphilic nanoparticles into double-layered plasmonic-magnetic vesicles in aqueous media. Reprinted from Reference [28] with permission.

Taking advantage of the selective affinities of ferrite and metals to bind different ligands, an asymmetric functionalization method was reported by Jishkariani et al. [29] to prepare Janus heterodimers from $\mathrm{Fe}_{3} \mathrm{O}_{4}-\mathrm{Pt}$ and $\mathrm{Fe}_{3} \mathrm{O}_{4}-\mathrm{Au}$ nanoparticles. Dendritic phosphonic acid and disulfide groups were used to coat the iron oxide and $\mathrm{Pt}$, respectively, or $\mathrm{Au}$ parts of the heterodimer to prepare amphiphilic structures (Figure 4). The synthesis involved 2,2-bis(hydroxymethyl)propionic acid (bis-MPA)-type disulfide dendrons 2, 4 and 6 with polar end-groups and a second-generation, stearate terminated, phosphonic acid bearing dendron 7 as the non-polar counterpart. Janus particles were prepared through sequential ligand exchange of the $\mathrm{Fe}_{3} \mathrm{O}_{4}-\mathrm{Pt}$ (or $\mathrm{Fe}_{3} \mathrm{O}_{4}$ - $\mathrm{Au}$ ) heterodimers.

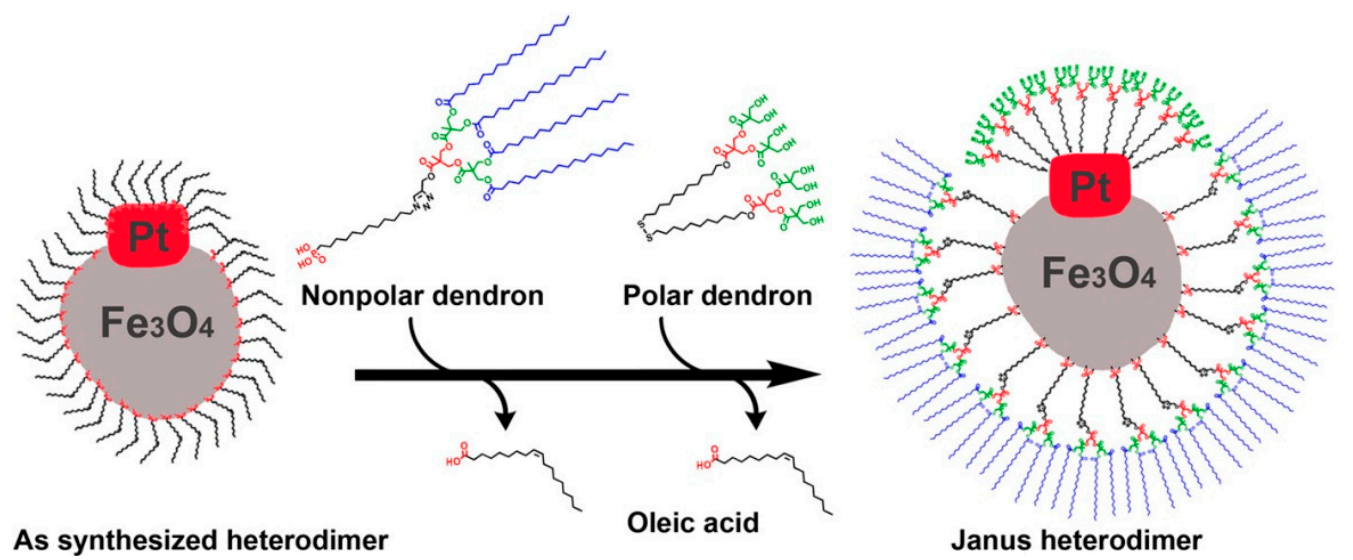

Figure 4. Schematic representation of the two-step ligand exchange process using dendritic ligands 7 and 6. Reprinted from Reference [29] with permission. 
With the smart materials' development, self-propelled motors have drawn great attention in biomedical science or environmental remediation fields [30]. Among the different synthetic strategies, the introduction of magnetic materials results in an efficient method to make controllable motors to perform tasks in targeted areas [31]. With this objective, recent efforts have focused on metal-oxide based materials. Peng et al. [32] reported an easy method for the fabrication of hollow three-dimensional graphene oxide (GO)/ $\mathrm{MnFe}_{2} \mathrm{O}_{4}$ motors by coupling shear force with capillarity. Figure 5 shows that the addition of aniline to aqueous suspensions of GO mixed with $\mathrm{MnFe}_{2} \mathrm{O}_{4}$ provoked a strong interaction which induced the effective aggregation of GO sheets giving rise to the subsequent turbulent flow structure under strong electric stirring. As a result, GO sheets spontaneously precipitated and gradually self-assembled into small 3D ball-shaped $\mathrm{GO} / \mathrm{MnFe}_{2} \mathrm{O}_{4}$ hydrogels with embedded $\mathrm{MnFe}_{2} \mathrm{O}_{4}$ particles. The surface was coated with a thin GO layer by dipping it again into aqueous GO. Then, a capillary force arising from the evaporation process was used to pull the $\mathrm{GO}$ sheets together and reassembled the aerogel into a $3 \mathrm{D}$ bowl-shaped macrostructure $\left(\mathrm{GO} / \mathrm{MnFe}_{2} \mathrm{O}_{4}\right.$ motor) with a great ability to adsorb heavy metal ions, this favoured by the abundant oxygen-containing groups on the GO surface.

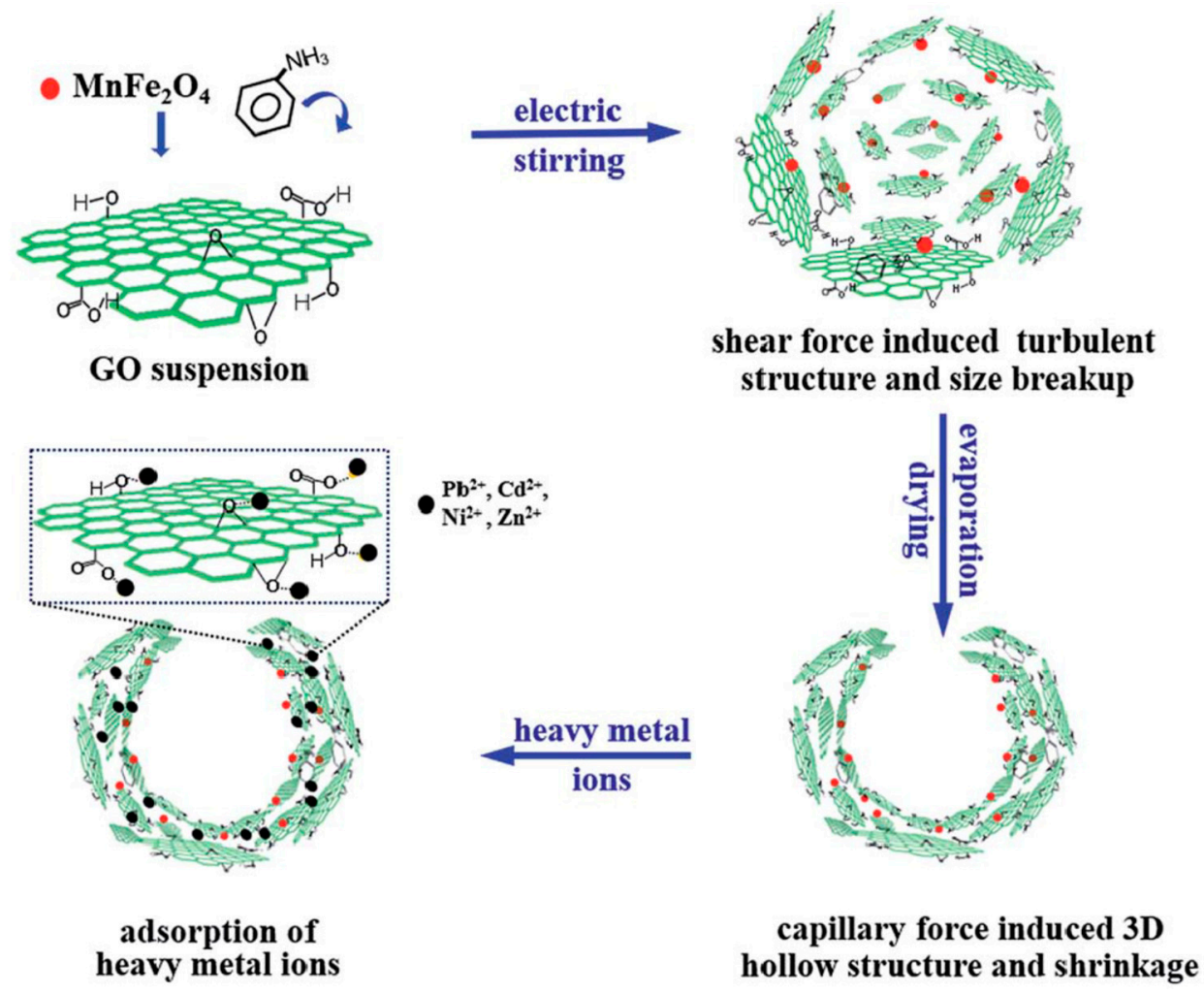

Figure 5. Scheme illustrating the self-assembly synthesis of a $\mathrm{GO} / \mathrm{MnFe}_{2} \mathrm{O}_{4}$ motor for the removal of heavy metal ions by shearing force driven breakup combined with capillary force induced shrinkage. Reproduced from Reference [32] with permission.

Magnetically steerable self-propelled Janus micromotors with ability to selectively remove radioactive Cs from contaminated water were synthesized from mesoporous silica microspheres functionalized with copper ferrocyanide and coating half of the surface with ferromagnetic $\mathrm{Ni}$ and catalytic Pt layers (Figure 6). Mesoporous silica was firstly functionalized with ethylenediamine (S-EDA), followed by preparation of $\mathrm{Cu}$ (II) coordination complexes (S-EDA-Cu) and reaction with sodium ferrocyanide (FC) to obtain S-CuFC particles. Thereafter, a poly(vinylpyrrolidone) (PVP)-coated glass slide was placed in a humidity-controlled chamber, where the humidity was raised until PVP became adhesive, so that when the synthesized S-CuFC particles were dispersed across the PVP layer, half of them were fixed inside the film and only the top surfaces of the particles were coated sequentially with a Ni layer and a Pt layer. The prepared S-CuFC/Ni/Pt Janus micromotors were released from the 
PVP-coated glass slide by sonication in ethanol [33]. It is important to note that the adsorption of Cs by the self-propelling micromotor adsorbents and their subsequent magnetic recovery provided the selective removing of more than $98 \%$ of the radioactive $137 \mathrm{Cs}$ ions from aqueous solutions.

(a)

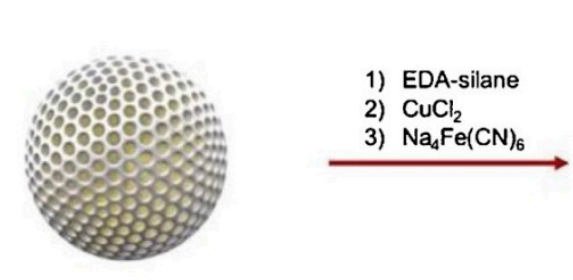

Mesoporous Silica microsphere

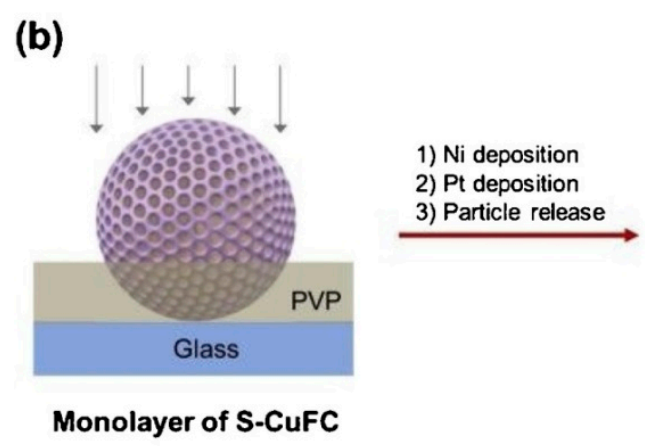

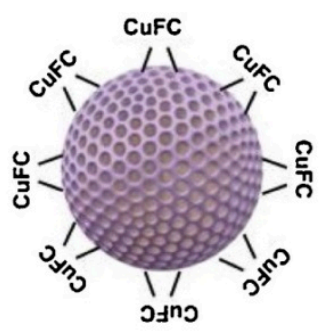

Copper ferrocyanide modified silica (S-CuFC)

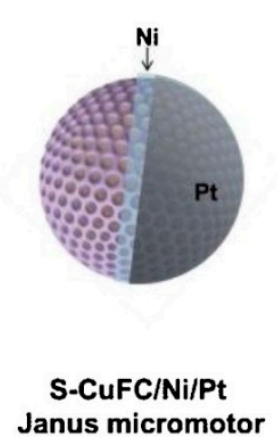

Figure 6. Scheme of the S-CuFC microspheres synthesis (a), and the sequential deposition of ferromagnetic Ni and catalytic Pt on half of the S-CuFC surface (b) for the fabrication of S-CuFC/Ni/Pt Janus micromotors. Reproduced from Reference [33] with permission.

\section{Magnetic Janus Particles for (Bio)Sensing}

Magnetic Janus particles combine anisotropy with magnetic properties, thus, delivering the ability to perform challenging tasks that would be impossible with isotropic particles. For example, a Janus particle may have the dual ability to stabilize an interface and to perform a catalytic reaction on some part of its surface [34]. This unique combination makes magnetic Janus particles interesting tools for a wide range of applications in different fields, such as catalysis [35], theranostic [36], drug delivery [37], biomedical imaging [7], biological probing, self-propelled carrier and remote manipulation of devices [7,38]. In addition, magnetic Janus particles can be used as surfactants, water-repellent coatings, or building blocks for supramolecular structures [38]. This section focuses on the implementation of Janus nanoparticles with a magnetic component for applications in static biosensing, but also including some examples of bioimaging, drug delivery and theranostic applications that involve a previous biosensing (target) step, as well as their use as biosensing self-propelled nanomachines. It is worth remarking here that even rare-earth-based Janus microparticles with magnetic and fluorescent functions have been reported and mostly used for drug delivery and bioapplications $[39,40]$.

\subsection{Static Janus Magnetic Particles for (Bio)Sensing}

The anisotropy in shape, composition, and surface chemistry of Janus nanoparticles allows their users to perform complementary functions, achieving an outcome not possible with conventional nanoparticles in the field of biosensing. Lu et al. reported an article showing the advantages of a magnetic bifunctional particle for glucose sensing using Janus particles with peroxidase-like activity for colorimetric detection of glucose in one step. The particles were more stable over a wider range 
of $\mathrm{pH}$ than the enzyme horseradish peroxidase (HRP) and, because of their magnetic nature, they allow easy sample separation/concentration, and can be reused by simple isolation through magnetic separation [41]. Taking advantage of this methodology, magnetic tailored microparticles with Janus structure, generated by using a centrifugal microfluidic chip, were exploited in a multi-assay format for the simultaneous sensing of glucose and cholesterol [42]. A competitive binding assay using fluorescein isothiocyanate-dextran as a competing ligand was employed for sensing glucose, and microparticles embedded with $\gamma-\mathrm{Fe}_{2} \mathrm{O}_{3}$ nanoparticles were used as a catalyst for the oxidation of tetramethylbenzidine by $\mathrm{H}_{2} \mathrm{O}_{2}$, a product of the enzymatic hydrolysis of cholesterol. Both sensing assays were integrated into the same Janus type particle, thus, allowing simultaneous monitoring of glucose and cholesterol in human serum.

Janus magnetic nanoparticles have also been used for DNA [43,44] and protein detection [45,46]. Doyle's group brilliantly developed polymeric magnetic Janus particles with separate detection and barcoding compartments [44,47]. The barcoding region displayed arrays of dots, while the sensing compartment was functionalized with DNA probe molecules for multiplexed detection. The magnetic microparticles incorporated into the Janus disks allowed rotation by an external magnetic field, enabling solution exchange through immobilization, particle decoding through orientation control and reaction enhancement through active stirring [44]. Regarding protein detection, multifunctional dumbbell-shaped magnetic Janus particles were prepared and modified on one face with anti-CD14 antibody for cell attachment and coated with anti-TNF $\alpha$ antibody on the other face (Figure 7a). The system allowed specific cell targeting and in situ multi-detection of cytokines [46].
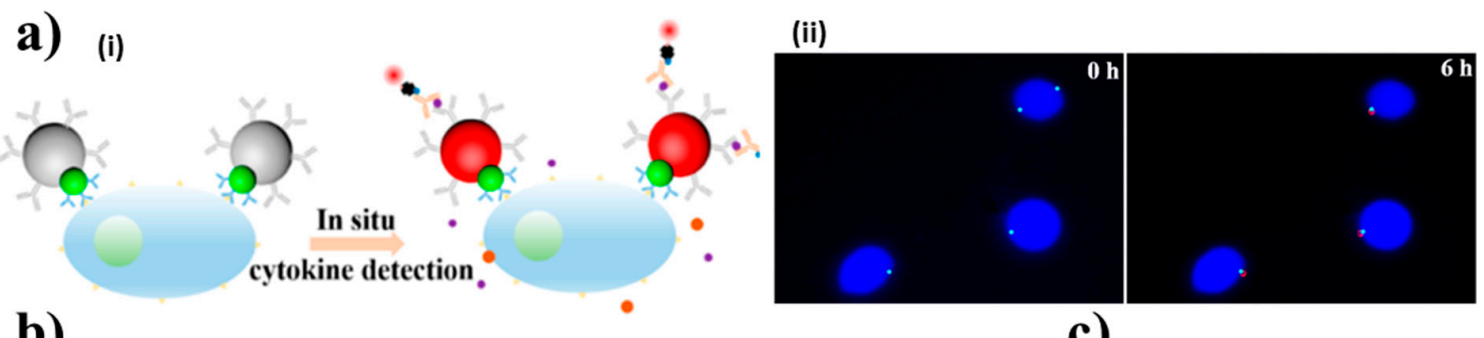

b)
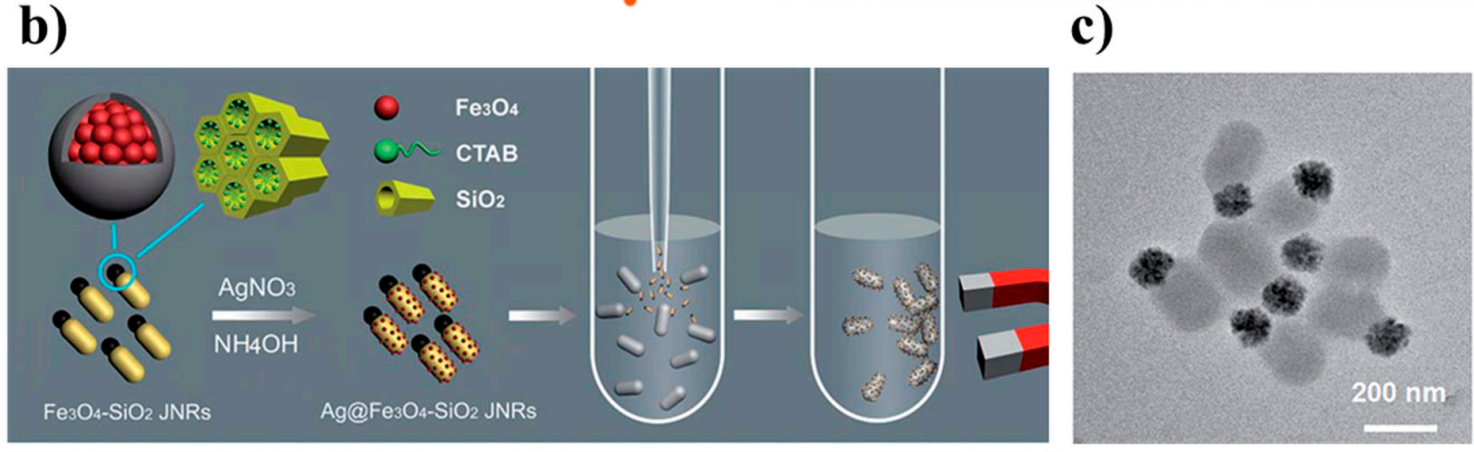

Figure 7. Scheme illustrating attachment of dumbbell particles to single cells and in situ sandwich Enzyme-Linked ImmunoSorbent Assay (ELISA) detection of cells released cytokine (i). Merged fluorescence images of the cell (blue) and dumbbell particles (green, small magnetic microspheres (sMS); red, big magnetic microspheres (bMS)) after ELISA detection. The images were taken at $6 \mathrm{~h}$ lipopolysaccharide (LPS) stimulation time. Cells were stained with CellTracker Blue CMAC (7-amino-4-chloromethylcoumarin) dye. Scale bar: $10 \mu \mathrm{m}$ (ii) (a). Schematic illustration of a typical procedure for the in situ synthesis of $\mathrm{AgNPs} @ \mathrm{Fe}_{3} \mathrm{O}_{4}-\mathrm{SiO}_{2}$ Janus nanorods (JNRs) and their sterilization and separation process (b). Magnetic Janus mesoporous silica nanoparticles Transmission Electron Microscope $($ TEM) images $(\mathrm{bar}=200 \mathrm{~nm})(\mathbf{c})$. Reprinted and adapted from Reference [46] (a), Reference [48] (b) and Reference [49] (c).

In several studies, magnetic JNPs have been used for the effective separation/concentration of biomaterials. Mirkin and coworkers developed triblock $\mathrm{Au}-\mathrm{Ni}-\mathrm{Au}$ nanorods for the detection and separation of protein mixtures $[50,51]$. The Au segments from the two-component triblock (Au-Ni-Au) 
nanorods were functionalized with nitrostreptavidin for capturing biotinylated proteins, and the $\mathrm{Ni}$ interior block was used as affinity template for simple and efficient separation of His-tagged proteins. In addition, the $\mathrm{Ni}$ portion of the nanorods is ferromagnetic, which enables easy isolation under a magnetic field. In this way, the authors demonstrated how the two-component triblock magnetic nanorods could be used to magnetically separate biotin-tagged proteins and His-tagged proteins from a mixed solution, thereby using a single material to separate and selectively remove multiple proteins and providing an alternative to the currently used affinity chromatography [51].

Multifunctional nanoplatforms based on the use of magnetic Janus mesoporous silica nanoparticles were designed to integrate bacterial capture, separation, and elimination into a single system $[48,49,52]$. In an interesting work, novel magnetic silica JNRs decorated with Ag nanoparticles (Figure 7b) showed superior magnetic sensitivity, strong binding to bacteria, and more effective and long-term antimicrobial activity than pure Ag nanoparticles. This was attributed to the properties of the formed nanocomposites with a variable AgNPs loading, which can significantly improve the dispersion and stability of the deposited AgNPs and enhance their bacteria binding capture efficiency [48]. Dong's group proposed the use of magnetic Janus mesoporous silica nanoparticles (MSNs) with hexadecyltrimethylammonium bromide (CTAB) loading, used both as a soft cationic template for mesoporous silica synthesis and anti-bacterial agent for bacterial elimination, and functionalized with amine groups, as nonselective ligands to bind both Gram-positive and Gram-negative bacteria via electrostatic attraction [53], as anti-bacterial drug [54]. In this way, the mesoporous silica body enhanced bacterial capture, due to its large surface, while the exposed $\mathrm{Fe}_{3} \mathrm{O}_{4}$ head maintained the strong paramagnetic property for bacterial separation [49]. To address specific bacteria targeting, fluorescent-magnetic Janus mesoporous silica nanoparticles were modified with a specific antibody. These JNPs acted as fluorescent identification and separation tools which enabled bacterial identification through Matrix-Assisted Laser Desorption Ionization Time-of-Flight Mass Spectrometry (MALDI-TOF-MS) directly from food matrixes [52].

Table 1 summarizes the main characteristics of the methodologies using magnetic Janus particles for static (bio)sensing applications.

Magnetic Janus Particles for Targeted Biomedical Applications

Nanoparticles have received great attention in the field of therapeutic and diagnostic. In particular, Janus particles, due to their two functional surfaces, can be used to selectively conjugate specific chemical moieties for drug delivery, non-invasive imaging, and/or targeted therapeutic intervention on a single-particle system [55]. Anisotropic nanoparticles have attracted great attention as multimodal imaging agents. In particular, magnetic nanoparticles can be used as contrast agents for magnetic resonance imaging (MRI) [7]. The incorporation of metallic nanoparticles provides plasmonic properties [56], and the subsequent modification with fluorescent dyes or quantum dots allows fluorescent imaging [57]. However, only a few systems have been reported involving specific target capacity into the magnetic Janus particles for imaging purposes. Dumbbell-shaped $\mathrm{Au}-\mathrm{Fe}_{3} \mathrm{O}_{4}[58]$ and $\mathrm{Ag}-\mathrm{Fe}_{3} \mathrm{O}_{4}$ [59] nanoparticles functionalized with specific antibodies against A431 human epithelial carcinoma cells and Raji and HeLa cells, respectively, were described. The high reflectance of the nanoparticles, due to the presence of the Au and Ag compartments, respectively, enabled optical visualization of cancer cells without fluorescence labeling, as well as MRI [58]. Recently, Sánchez et al. reported an elegant Janus nanoplatform by combining a $\mathrm{Fe}_{3} \mathrm{O}_{4} \mathrm{NPs} /$ mesoporous silica core@shell face together with an Au nanoparticle face [60]. Due to its anisotropy, the resulting hybrid nanocarriers successfully allowed the in vivo tumor-targeted (by its modification with a targeting peptide for cancer detection cRGD motif) multimodal MRI ( $\mathrm{Fe}_{3} \mathrm{O}_{4}$ core), computed tomography (CT, AuNP face) and fluorescent tracking (fluorescent dye loading) in a fibrosarcoma-bearing mouse model (Figure 8). Moreover, in vitro experiments performed by $24 \mathrm{~h}$ incubation with HEK293, HepG2, RAW 264.7, adult fibroblasts (MAF), and fibrosarcoma (MF) mouse cells confirmed the biocompatibility of these Janus particles within the tested concentration range $\left(35-350 \mu \mathrm{g} \mathrm{mL}^{-1}\right)$. 
Table 1. Janus magnetic particles for static (bio)sensing.

\begin{tabular}{|c|c|c|c|c|c|}
\hline Composition & Morphology & Preparation Method & Application & Target Analyte & Ref. \\
\hline $\begin{array}{l}\text { Magnetic Janus mesoporous } \\
\text { silica nanoparticles }\end{array}$ & Rod & Sol-gel method & $\begin{array}{l}\text { Capture, separation and } \\
\text { elimination }\end{array}$ & $\begin{array}{c}\text { Escherichia coli and } \\
\text { Staphylococcus aureus on } \\
\text { LB-agar plates }\end{array}$ & [49] \\
\hline $\begin{array}{l}\text { Magnetic Janus mesoporous } \\
\text { silica nanoparticles }\end{array}$ & Rod & Sol-gel method & Capture and identification & $\begin{array}{l}\text { Foodborne bacteria in milk } \\
\text { samples }\end{array}$ & [52] \\
\hline $\mathrm{Au}-\mathrm{Ni}-\mathrm{Au}$ & Rod & Porous template synthesis & $\begin{array}{c}\text { Therapeutics and } \\
\text { separations }\end{array}$ & $\begin{array}{l}\text { Separation His-tagged proteins } \\
\text { and } \mathrm{Ab} \text { to poly-His }\end{array}$ & [50] \\
\hline Encoded particles & - & Stop-flow lithography & $\begin{array}{l}\text { Determination and } \\
\text { identification }\end{array}$ & miRNAs & [44] \\
\hline$\gamma-\mathrm{Fe}_{2} \mathrm{O}_{3}-\mathrm{SiO}_{2} / \mathrm{Glucose}$ oxidase & Sphere & $\begin{array}{l}\text { One-step flame-assisted } \\
\text { spray-pyrolysis }\end{array}$ & Enzymatic biosensing & Glucose & [41] \\
\hline $\begin{array}{l}\text { NitroStrep-Au-Ni- } \\
\text { Au-NitroStrep }\end{array}$ & Rod & Porous template synthesis & $\begin{array}{l}\text { Magnetic protein } \\
\text { separation }\end{array}$ & $\begin{array}{l}\text { Separation of a mixture of } \\
\text { Histag-Uniquitin, Biotin-BSA } \\
\text { and protein A }\end{array}$ & [51] \\
\hline $\begin{array}{c}\text { Con } \\
\text { A/dextran- } \gamma-\mathrm{Fe}_{2} \mathrm{O}_{3} / \text { esterase }\end{array}$ & Sphere & Centrifugal microfluidic chip & Enzymatic biosensing & $\begin{array}{c}\text { Glucose and cholesterol in } \\
\text { serum samples }\end{array}$ & [42] \\
\hline $\begin{array}{c}\text { EMG } 507 \text { ferrofluid/polymeric } \\
\text { phase (PEGDA) }\end{array}$ & Sphere & $\begin{array}{l}\text { Droplet micromagnetofluidic } \\
\text { technique }\end{array}$ & Protein detection & BSA & [45] \\
\hline $\begin{array}{l}\text { Janus Hydrogel particles } \\
\left(\mathrm{Fe}_{3} \mathrm{O}_{4} / \mathrm{PEG} / \text { Darocur }\right)\end{array}$ & Acorn & Microfluidic synthesis & $\begin{array}{c}\text { Bioimaging and } \\
\text { imaging-guided therapies }\end{array}$ & DNA detection & [43] \\
\hline $\mathrm{AgNPs} @ \mathrm{Fe}_{3} \mathrm{O}_{4}-\mathrm{SiO}_{2}$ & Rod & Sol-gel method & Antimicrobial & $\begin{array}{c}\text { Escherichia coli and Bacillus } \\
\text { subtilis }\end{array}$ & [48] \\
\hline TCO-bMS and Tz-sMS & Dumbbell & Click Chemistry & $\begin{array}{l}\text { Bioimaging, single-cell } \\
\text { analysis and biomedical } \\
\text { diagnostics }\end{array}$ & $\begin{array}{l}\text { In situ TNF } \alpha \text { detection released } \\
\text { by cancer cells. }\end{array}$ & [46] \\
\hline
\end{tabular}

$\mathrm{Ab}$, antibody; bMS, big magnetic microspheres; BSA, bovine serum albumin; LB, Luria-Bertani broth; PEG, polyethylene glycol; PEGDA, polyethylene glycol diacrylate; TCO, trans-cyclooctene; TzMS, tetrazine magnetic microspheres. 


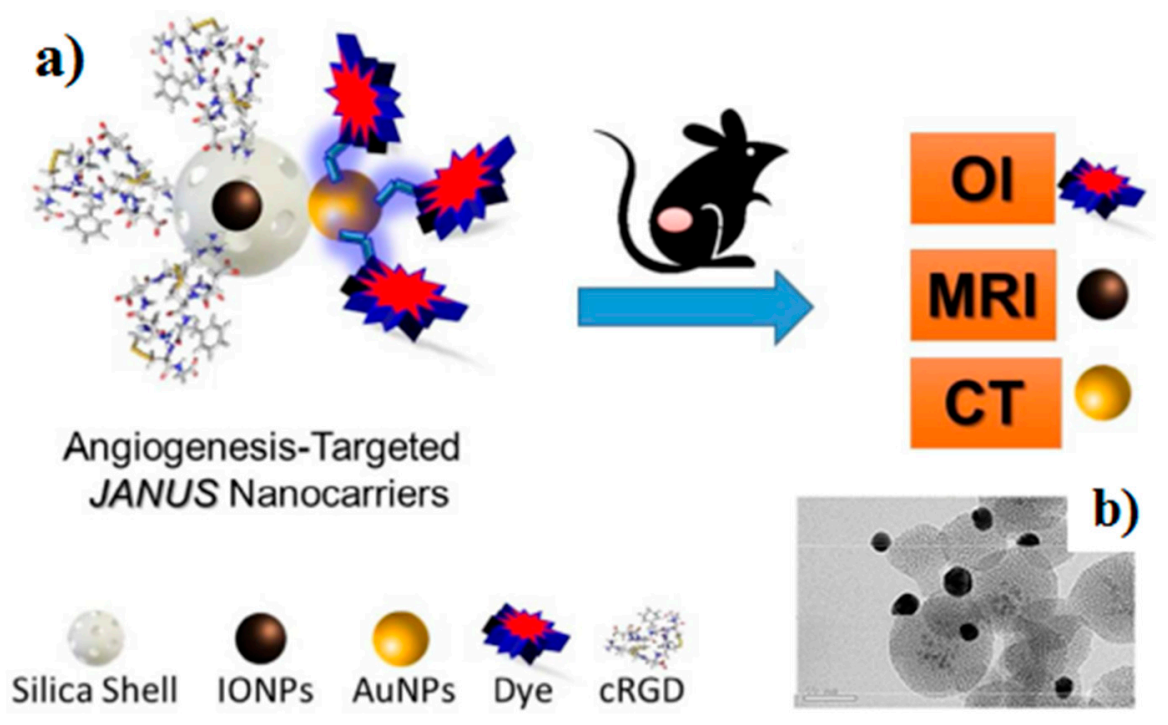

Figure 8. Strategy for multimodal molecular imaging assessment of targeted Janus nanoparticles in tumor-bearing mouse model (OI, optical imaging; MRI, magnetic resonance imaging; CT, computed tomography; IONPs, iron oxide nanoparticles; cRGD, peptide cyclo[Arg-Gly-Asp-D-Phe-Lys]). Reprinted and adapted from Reference [60].

The intrinsic heterogeneity of Janus particles makes them suitable for delivering drugs with different properties, unlike core-shell nanoparticles [61]. In drug delivery systems, specific targeting is crucial to avoid damage to healthy cells and to enhance the drug bioavailability [20]. Thus, some controlled release magnetic Janus particles have been conjugated with specific ligands for specific drug release targeting. In this context, dumbbell-like $\mathrm{Au}-\mathrm{Fe}_{3} \mathrm{O}_{4}$ nanoparticles were prepared as target-specific nanocarriers to deliver cis-Pt complexes into epidermal growth factor receptor 2 (HER2)-positive breast cancer cells. In this structure, the Pt complex was anchored on the Au side and the HER2-specific monoclonal antibody Herceptin, chosen as a targeting agent, was linked to $\mathrm{Fe}_{3} \mathrm{O}_{4}$ side [62]. Following a similar strategy of active targeting and drug delivery, cell targeting and intracellular DNA magnetic-controlled release in cancer cells were also achieved by using magnetic Janus nanocapsules [63]. In addition, Wang et al. prepared super-paramagnetic Janus nanocomposites of polystyrene/ $\mathrm{Fe}_{3} \mathrm{O}_{4} @ \mathrm{SiO}_{2}$ structure with dual functionalities for drug delivery applications. To achieve simultaneous cell targeting and stimulus-induced drug release, the polystyrene matrix was surface-decorated with carboxyl groups where the tumor cell targeting was attempted by the conjugation of folic acid, whereas the antitumor agent DOX was immobilized to the silica shell via a $\mathrm{pH}$-sensitive hydrazone bond, thus, facilitating $\mathrm{pH}$-induced drug release [64].

An exciting trend in drug delivery is incorporating therapeutic, targeting, and imaging all in one particle. Kilinc et al. synthesized Fe-Au nanorods for combined cell targeting, therapy and imaging able to specifically target breast cancer cells. In this design, the Au block was modified with heregulin, a ligand of HER family of receptors, whereas the magnetic response of the Fe block was used for mechanical perturbation and MRI [65]. A very nice work reported by Zhang et al. describes a method for the synthesis of uniform multifunctional $\mathrm{Au} / \mathrm{Fe}_{3} \mathrm{O}_{4} @ \mathrm{C}$ Janus nanoparticles. These nanoparticles were selectively functionalized with amino-poly(ethyleneglycol)thiol and folic acid on the exposed Au domains (Figure 9) to achieve high contrast for computed tomography imaging, excellent stability, good biocompatibility, as well as cancer cell-specific targeting. The mesoporous structure was used as a carrier for DOX, photothermal agent and MRI contrast agent [66]. New magnetic-luminescent multifunctional nanoparticles $\left(\mathrm{MnFe}_{2} \mathrm{O}_{4}-\mathrm{NaYF}_{4}\right)$ were modified with folic acid to target human esophagus carcinoma cells. The system exhibited multiple uses, including multimodal imaging, targeted drug delivery, and cancer imaging-guided therapies [67]. Following the same trend of theranostics approach, monodisperse $\mathrm{Au}-\mathrm{Fe}_{2} \mathrm{C}$ Janus nanoparticles were synthesized as multifunctional 
entities for cancer theranostics. The entities had triple-modal magnetic resonance/multispectral photoacoustic tomography/computed tomography imaging-guided for precise diagnosis and efficient tumor treatment through laser radiation. In vitro and in vivo targeting was achieved by modifying the $\mathrm{Au}-\mathrm{Fe}_{2} \mathrm{C}$ Janus particles with an affibody (ZHER2:342), showing a larger tumor accumulation and deeper tumor penetration than the non-targeted ones [68].

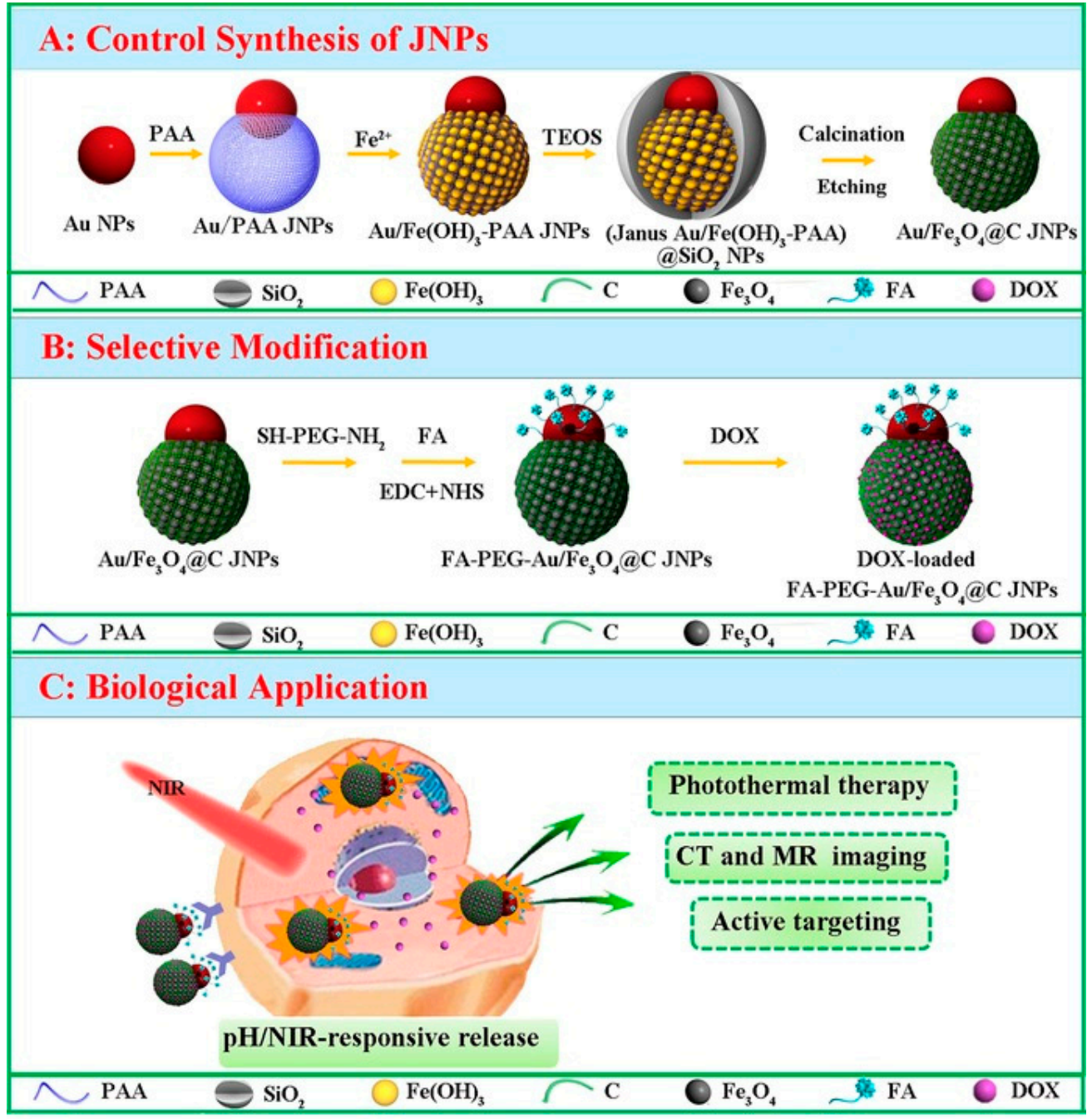

Figure 9. Scheme showing the controlled synthetic strategy for obtaining $\mathrm{Au} / \mathrm{Fe}_{3} \mathrm{O}_{4} @ \mathrm{C} \mathrm{JNPs}$ (A). Selective modification of $\mathrm{Au} / \mathrm{Fe}_{3} \mathrm{O}_{4} @ \mathrm{C}$ JNPs (B). Biological application of FA-PEG-Au/ $/ \mathrm{Fe}_{3} \mathrm{O}_{4} @ \mathrm{C}$ JNPs for simultaneous dual-modal imaging and actively targeted chemo-photothermal synergistic therapy of cancer cells (C). Reprinted with permission from Reference [66].

The main aspects of targeted (bio)imaging and biomedical applications using magnetic Janus particles are outlined in Table 2. 
Table 2. Janus magnetic particles for targeted (bio)imaging and biomedical applications.

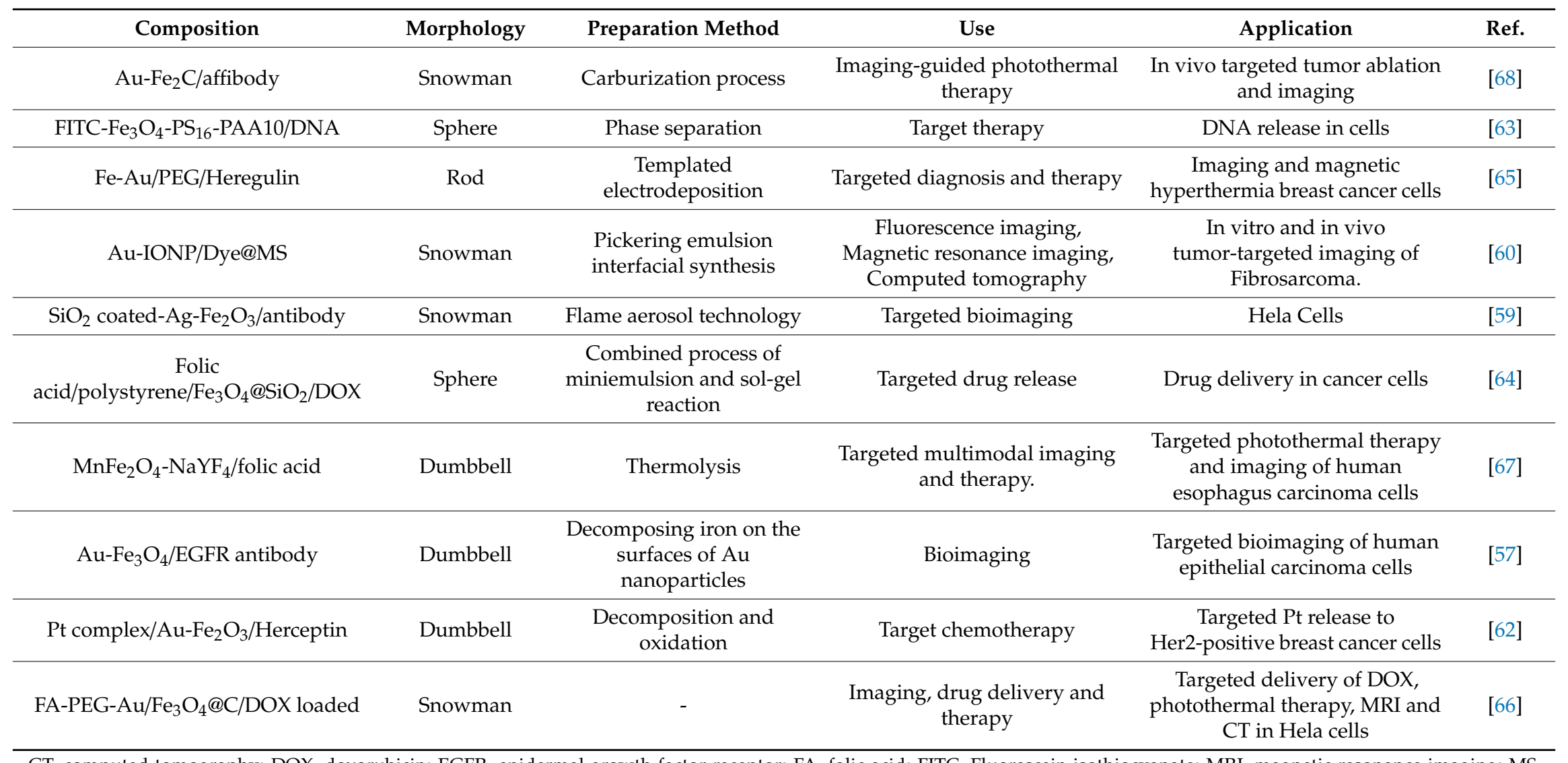

CT, computed tomography; DOX, doxorubicin; EGFR, epidermal growth factor receptor; FA, folic acid; FITC, Fluorescein isothiocyanate; MRI, magnetic resonance imaging; MS, mesoporous silica; IONP, iron oxide nanoparticles; PEG, polyethylene glycol; PS16-PAA10, poly(styrene allyl alcohol). 


\subsection{Self-Propelled Janus Magnetic Particles for (Bio)Sensing}

Under certain experimental conditions, Janus particles can be propelled autonomously (Janus motors). This self-propulsion can be achieved through certain electrochemical reactions or the incorporation of metals $(\mathrm{Pt}, \mathrm{Mg}$ ) capable of generating gaseous bubbles in the presence of certain fuels $\left(\mathrm{H}_{2} \mathrm{O}_{2}\right.$, water). The inherent lack of a defined trajectory can be solved by including a magnetic component (usually nickel) in the Janus motor structure, which allows their guidance or isolation in the presence of an external magnetic field. Self-propelled Janus magnetic particles using metals, polymers or carbon materials have been reported so far.

Self-propelled Janus magnetic particles, unmodified or functionalized with appropriate bioreceptors, have demonstrated to possess unrivaled merits for optical and electrochemical on-site sensing and biosensing of a wide variety of analytes and biomolecules (nucleic acids, proteins, cancer and bacterial cells and other clinically relevant analytes, such as cortisol) in near real-time. Table 3 summarizes the main features of the biosensing strategies that were reported involving the use of self-propelled Janus magnetic particles. It is important to note that the autonomous movement of the Janus magnetic particles has been decisive in developing efficient and rapid biosensing strategies involving 'on-the-move' recognition and (bio)sensing events in complex samples without preparatory and washing steps $[4,7,8,11,15,69-73]$. This autonomous movement around the sample addresses the low binding efficiency associated with the slow analyte transport occurring in bioaffinity sensors working in quiescent sample droplets, thus, increasing the likelihood of target-receptor contacts and greatly enhancing the kinetic and sensitivity of the (bio)sensing event [11].

To date, the use of self-propelled Janus magnetic motors for biosensing involving trimetallic nanowires, tubular micromotors or spherical particles has been reported (Figure 10). In these biosensing applications, the signal transduction was achieved through: (1) Chemical sensing involving measurement of the speed and/or distance the motors travelled at fixed times in the presence of the target analytes [74,75]; (2) electrochemical sensing by electrochemical detection of electroactive compounds generated by degradation of non-electroactive compounds using Janus particles with artificial enzymatic activity [76] or by using particle-electrode impact voltammetry to quantify and qualify locomotion of self-propelled micromotors [77]; and (3) optical and fluorescent sensing by monitoring directly captured big target analytes (cells and bacteria) $[78,79]$ or in connection with appropriate fluorescent labels $[80,81]$ or quenching mechanisms $[82,83]$.

(a)
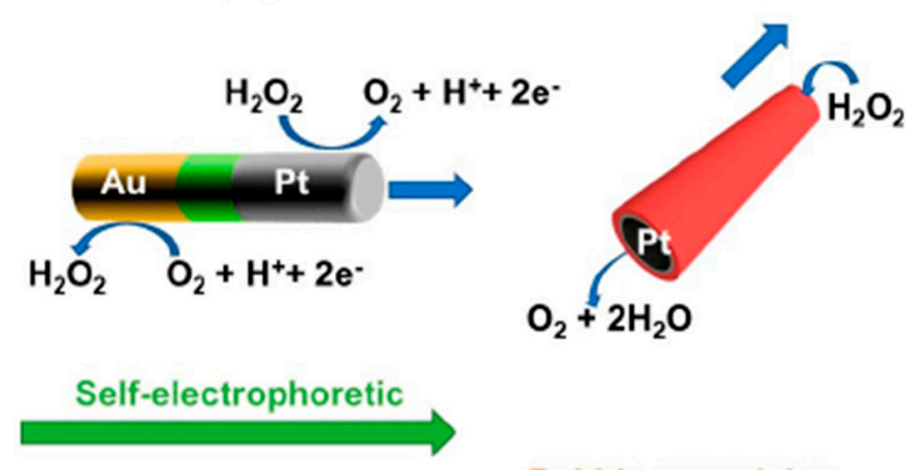

(b)

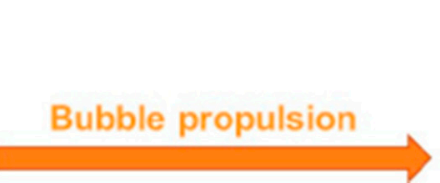

(c)

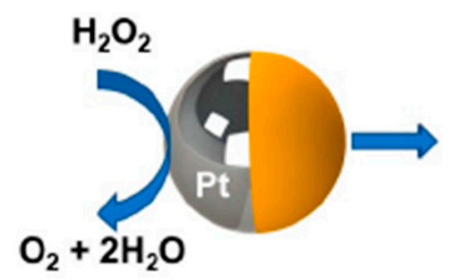

Self-electrophoretic

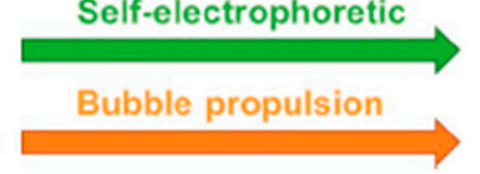

Figure 10. Magnetic Janus motors for biosensing applications and related propulsion mechanisms: Nanowires (a), tubular micromotors (b) and spherical particles (c). Reprinted from Reference [15] with permission. 
Table 3. Self-propelled Janus magnetic particles for (bio)sensing.

\begin{tabular}{|c|c|c|c|c|c|c|c|}
\hline $\begin{array}{c}\text { Type of Self-Propelled Janus } \\
\text { Magnetic Particles }\end{array}$ & $\begin{array}{c}\text { Propulsion } \\
\text { Mechanism (Fuel) }\end{array}$ & Fundamentals & Type of Detection & Target Analyte & $\begin{array}{c}\text { Analytical } \\
\text { Characteristics }\end{array}$ & Sample & Ref. \\
\hline Au-Ni-Pt nanowires & $\begin{array}{l}\text { Self-electrophoretic } \\
\text { propulsion } \\
\text { mechanism } \\
\left(\mathrm{H}_{2} \mathrm{O}_{2}\right)\end{array}$ & $\begin{array}{l}\text { Selective acceleration in the } \\
\text { presence of silver ions }\left(\mathrm{Ag}^{+}\right) \text {in } \\
\text { connection with sandwich DNA } \\
\text { hybridization approach onto a } \\
\text { photolithography-prepared gold } \\
\text { electrode }\end{array}$ & $\begin{array}{l}\text { Optical (speed/distance } \\
\text { travelled) }\end{array}$ & $\begin{array}{l}\text { 30-mer } \\
\text { synthetic DNA } \\
\text { or E. coli 16S } \\
\text { mRNA }\end{array}$ & $\begin{array}{l}40 \text { amol (synthetic } \\
\text { DNA), } 2000 \text { cfus } \\
\mathrm{mL}^{-1} \text { of } E \text {. coli }\end{array}$ & $\begin{array}{l}\text { untreated bacterial } \\
\text { lysates }\end{array}$ & [75] \\
\hline $\begin{array}{l}\text { Photolithography prepared } \\
\mathrm{Pt} / \mathrm{Au} / \mathrm{Ni} / \mathrm{Ti} \text { microtubes }\end{array}$ & $\begin{array}{l}\text { Bubble propulsion } \\
\left(\mathrm{H}_{2} \mathrm{O}_{2}+\mathrm{NaCh}\right)\end{array}$ & $\begin{array}{l}\text { Sandwich DNA hybridization } \\
\text { assay onto thiolated DNA capture } \\
\text { probe modified microtubes }\end{array}$ & $\begin{array}{c}\text { Indirect fluorescent } \\
\text { (streptavidin fluorescent } \\
\text { nanoparticles) }\end{array}$ & $\begin{array}{l}\text { 30-mer } \\
\text { synthetic DNA } \\
\text { or E. coli 16S } \\
\text { mRNA }\end{array}$ & $\begin{array}{l}\sim 25 \mathrm{nM} \text { synthetic } \\
\text { target DNA }\end{array}$ & $\begin{array}{c}\text { Spiked } 100 \% \text { human } \\
\text { serum, } 10 \% \text { human } \\
\text { urine and saliva and } \\
\text { raw bacterial lysates }\end{array}$ & [80] \\
\hline $\begin{array}{l}\text { Photolithography prepared } \\
\mathrm{Pt} / \mathrm{Au} / \mathrm{Ni} / \mathrm{Ti} \text { microtubes }\end{array}$ & $\begin{array}{l}\text { Bubble propulsion } \\
\left(\mathrm{H}_{2} \mathrm{O}_{2}+\mathrm{NaCh}\right)\end{array}$ & $\begin{array}{l}\text { Sandwich aptameric assay onto } \\
\text { thiolated aptameric capture probe } \\
\text { modified microtubes }\end{array}$ & $\begin{array}{c}\text { Indirect fluorescent } \\
\text { (streptavidin fluorescent } \\
\text { nanoparticles) }\end{array}$ & $\begin{array}{l}\text { Human } \\
\text { thrombin }\end{array}$ & $\sim 100 \mathrm{nM}$ & $\begin{array}{l}\text { Spiked untreated serum } \\
\text { and plasma pretreated } \\
\text { to precipitate fibrinogen }\end{array}$ & [81] \\
\hline $\begin{array}{l}\text { Photolithography prepared } \\
\mathrm{Pt} / \mathrm{Au} / \mathrm{Ni} / \mathrm{Ti} \text { microtubes }\end{array}$ & $\begin{array}{l}\text { Bubble propulsion } \\
\left(\mathrm{H}_{2} \mathrm{O}_{2}+\mathrm{NaCh}\right)\end{array}$ & $\begin{array}{l}\text { Selective recognition onto anti } \\
\text { CEA-modified microtubes }\end{array}$ & Direct optical & $\begin{array}{l}\text { CEA+ cancer } \\
\text { cells }\end{array}$ & $?$ & $\begin{array}{l}\text { 1:4 diluted human } \\
\text { serum }\end{array}$ & [78] \\
\hline $\begin{array}{c}\text { Template electrodeposited } \\
\mathrm{Au} / \mathrm{Ni} / \mathrm{PANI} / \mathrm{Pt} \text { microtubes }\end{array}$ & $\begin{array}{l}\text { Bubble propulsion } \\
\left(\mathrm{H}_{2} \mathrm{O}_{2}+\mathrm{NaCh}\right)\end{array}$ & $\begin{array}{l}\text { Selective recognition onto } \\
\text { ConA-modified microtubes }\end{array}$ & Direct optical & E. coli & $?$ & $\begin{array}{l}\text { Spiked drinking water, } \\
\text { apple juice and seawater }\end{array}$ & [79] \\
\hline $\begin{array}{l}\text { Template electrodeposited } \\
\mathrm{Au} / \mathrm{PEDOT} / \mathrm{Ni} / \mathrm{Pt} \text { microtubes }\end{array}$ & $\begin{array}{l}\text { Bubble propulsion } \\
\left(\mathrm{H}_{2} \mathrm{O}_{2}+\mathrm{NaCh}\right)\end{array}$ & $\begin{array}{l}\text { Direct competitive immunoassay } \\
\text { using cortisol-HRP onto } \\
\text { anticortisol-modified microtubes }\end{array}$ & $\begin{array}{c}\text { Indirect } \\
\text { optical/naked-eye using } \\
\mathrm{H}_{2} \mathrm{O}_{2} / \mathrm{TMB} \\
\end{array}$ & Cortisol & $0.1 \mu \mathrm{g} \mathrm{mL}^{-1}$ & $?$ & [84] \\
\hline Au-Ni-Mg Janus particles & $\begin{array}{l}\text { Bubble propulsion } \\
\quad \text { (water) }\end{array}$ & $\begin{array}{l}\text { Produce } \mathrm{OH}^{-} \text {ions to increase the } \\
\text { medium } \mathrm{pH} \text { and promote the } \\
\text { paraoxon degradation }\end{array}$ & $\begin{array}{c}\text { Amperometric }(+0.9 \mathrm{~V} \\
\text { vs. } \mathrm{Ag} / \mathrm{AgCl})\end{array}$ & Paraoxon & $\sim 4 \mathrm{mM}$ & $?$ & [76] \\
\hline $\begin{array}{c}\text { Magnetocatalytic hybrid } \\
\text { Janus spherical particles } \\
\text { (GQDs, PtNPs and } \mathrm{Fe}_{3} \mathrm{O}_{4} \mathrm{NPs} \text { ) } \\
\text { modified with PABA }\end{array}$ & $\begin{array}{c}\text { Magnetic and } \\
\text { bubble propulsion } \\
\left(\mathrm{H}_{2} \mathrm{O}_{2}+\mathrm{NaCh}\right)\end{array}$ & $\begin{array}{l}\text { Interaction between } \\
\text { PABA-modified GQDs and } \\
\text { targeted bacterial LPS }\end{array}$ & Fluorescence quenching & E. coli & $?$ & $\begin{array}{l}\text { Unprocessed urine and } \\
\text { serum samples }\end{array}$ & [82] \\
\hline $\begin{array}{c}\text { Magnetocatalytic hybrid } \\
\text { Janus spherical particles } \\
\text { (GQDs, PtNPs and } \mathrm{Fe}_{3} \mathrm{O}_{4} \mathrm{NPs} \text { ) } \\
\text { modified with PABA }\end{array}$ & $\begin{array}{l}\text { Magnetic and } \\
\text { bubble propulsion } \\
\left(\mathrm{H}_{2} \mathrm{O}_{2}+\mathrm{NaCh}\right)\end{array}$ & $\begin{array}{l}\text { Interaction between } \\
\text { PABA-modified GQDs and } \\
\text { targeted bacterial LPS }\end{array}$ & Fluorescence quenching & $\begin{array}{l}\text { Salmonella } \\
\text { enterica }\end{array}$ & $\begin{array}{l}0.07 \mathrm{ng} \mathrm{mL}^{-1} \text { of } \\
\text { endotoxin }\end{array}$ & $\begin{array}{l}\text { Spiked milk, mayo, egg } \\
\text { yolk, and egg white }\end{array}$ & [83] \\
\hline
\end{tabular}

CEA, carcioembriogenic antigen; ConA, Concanavalin A; GQDs, graphene quantum dots; HRP, horseradish peroxidase; PABA, phenylboronic acid; LPS, lipopolysaccharides; PANI polyaniline; $\mathrm{PEDOT}$, poly(3,4-ethylenedioxythiophene); TMB, 3,3',5,5'-tetramethylbenzidine. 
Wang's group, from the University of California San Diego, pioneered the use of magnetic Janus motors for optical biosensing. In particular, Au-Ni-Pt nanowires were prepared for the determination of nucleic acids [75]. These catalytic nanowires are able to self-propel at speeds of $\sim 10 \mu \mathrm{m} \mathrm{s}^{-1}$ in a solution containing $5-10 \%$ of $\mathrm{H}_{2} \mathrm{O}_{2}$. Platinum catalyzed the oxidation of $\mathrm{H}_{2} \mathrm{O}_{2}$, which generated electrons and free protons at that end of the nanomotor. Due to the structure of the nanowire, asymmetric distribution of charges and an electrical gradient was generated, which translated into the autonomous advancement of the nanomotor in the direction in which the platinum end pointed (Figure 11a). Taking advantage of the selective acceleration of these nanomotors in the presence of silver ions, attributed to the improved catalytic activity of platinum after underpotential deposition of silver on the nanowires [74], this group developed a strategy for nucleic acid biosensing using for the first time the distance traveled by the nanomotor as an analytical signal [75]. The biosensing strategy was used for the quantification of synthetic DNA and bacterial rRNA and involved a detector probe modified with Ag nanoparticles in a typical hybridization sandwich format. The assay implied co-self-assembly of a thiolated specific DNA capture probe and dithiotreitol (DTT) and post-treatment with mercaptohexanol $(\mathrm{MCH})$ on a photolithography-prepared gold electrode followed by sequential incubation on this modified surface with the sample containing the target DNA and the Ag nanoparticles-modified detector probe. Upon placing a drop of an $\mathrm{H}_{2} \mathrm{O}_{2}$ solution on the electrode surface with the immobilized DNA sandwich, the Ag nanoparticles were rapidly dissolved and, after mixing the $\mathrm{Ag}^{+}$enriched solution with a nanomotors suspension, their speed was monitored for a fixed time (Figure 11a). The higher the concentration of target nucleic acid (30-mer synthetic DNA or Escherichia coli (E. coli) $16 \mathrm{~S}$ mRNA), the larger the number of nanoparticles captured and, therefore, the higher the speed (or the distance travelled at a fixed time) of the nanomotors. This new biosensing principle was able to selectively detect 40 amol synthetic DNA and 2000 colony forming units (cfus) mL $\mathrm{mL}^{-1}$. coli directly in untreated bacterial lysates. In addition, the principle facilitates the collection of multiple readings in a single experiment, reduces the likelihood of false positives or negatives, and can be easily extended to other biosensing strategies. Despite these interesting features, catalytic nanowires operation is restricted to low ionic strength environments, which limits their usefulness for biosensing purposes $[11,69]$. This is the reason why tubular micromotors and spherical particles, which efficiently propel in high ionic concentration environments and complex biological fluids, have been much more used for dynamic biosensing [15].

Microtubes with the internal catalytic surface of $\mathrm{Pt}$ are chemically propelled by $\mathrm{O}_{2}$ bubbles generated by the decomposition of $\mathrm{H}_{2} \mathrm{O}_{2}$ in the presence of a suitable surfactant (Figure 11b) [69]. In addition, the incorporation of the ferromagnetic Ni intermediate layer makes it easy to be guided with a magnet. These microtubes were initially manufactured with standard photolithography techniques [80,81] and more recently by electrodeposition in commercial membranes [79,84], which is a much cheaper and simpler methodology that also allows the motor size to be modulated at will for each particular application. These micro-rockets can be modified with gold by electroplating, only on half of their external surface (Figure $11 b, c$ ) to facilitate their modification with different bioreceptors, and, therefore, they can be considered Janus motors. 

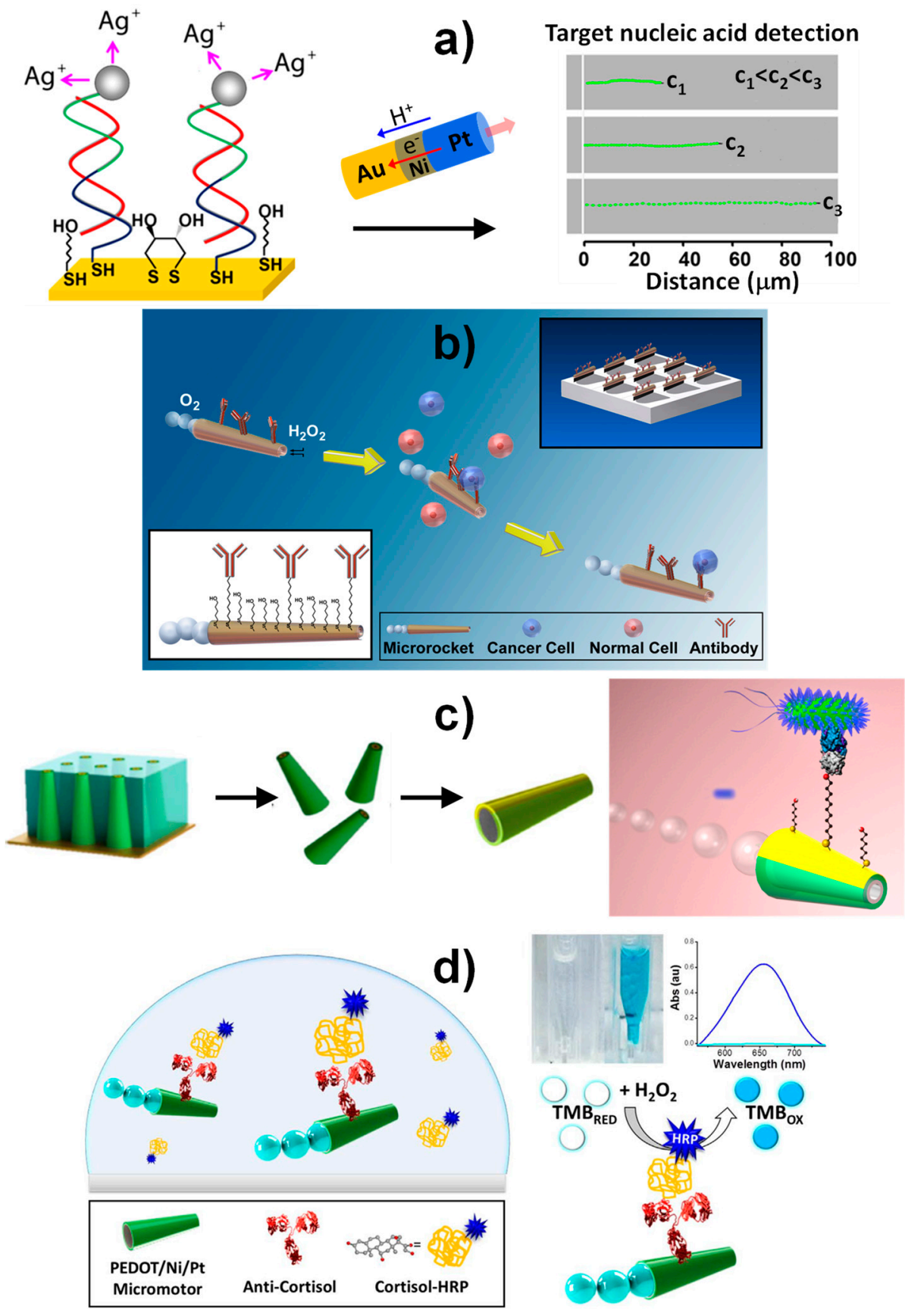

Figure 11. Optical biosensing using catalytic magnetic Janus motors (a) and tubular motors prepared by top-down photolithography (b) or template electrodeposition $(\mathbf{c}, \mathbf{d})$. Detection of: Nucleic acids with catalytic Au-Ni-Pt nanowires (a), cancer cells with Ti/Ni/Au/Pt microtubes modified with antibodies (b) bacteria with lectin-modified $\mathrm{Au} / \mathrm{Ni} / \mathrm{PANI} / \mathrm{Pt}$ microtubular engines (c) and naked-eye detection of cortisol with antibodies-functionalized Au/PEDOT/Ni/Pt microtubes (d). Reprinted and adapted from Reference [75] (a), Reference [78] (b), Reference [79] (c) and Reference [84] (d) with permission.

Although these micro-rockets can travel at up to $2 \mathrm{~mm} \mathrm{~s}^{-1}$, after the functionalization required conferring the necessary selectivity in biosensing applications they typically navigate at $100-200 \mu \mathrm{m} \mathrm{s}^{-1}$ (in biological samples supplemented with $1-5 \%(w / v) \mathrm{H}_{2} \mathrm{O}_{2}$ and $0.25-2 \%(w / v)$ sodium cholate surfactant, $\mathrm{NaCh}$ ). This is sufficient speed to ensure their prolonged navigation ( $>30 \mathrm{~min}$ ) in complex and viscous biological media. The reported results show that the required $\mathrm{H}_{2} \mathrm{O}_{2}$ and $\mathrm{NaCh}$ concentrations affect neither the functionalization used to immobilize the bioreceptors nor the efficiency of the biological 
interactions required for biosensing. The speed of these microtransporters allows the rapid scanning of a sample, ensuring the probability of interaction of the target analyte with the surface-confined receptors. In addition, the convection currents and vortex effect associated with this movement and the generated bubbles create a very favorable hydrodynamic environment that accelerates the (generally slow) kinetics of the recognition reactions, allowing the development of efficient, simple biosensing strategies in near real-time $[11,80]$.

$\mathrm{Pt} / \mathrm{Au} / \mathrm{Ni} / \mathrm{Ti}$ microtubes were prepared by photolithography or by template electrodeposition of $\mathrm{Pt}$ and poly(3,4-ethylenedioxythiophene) (PEDOT) or polyaniline (PANI) on commercial membranes and modified with $\mathrm{Au}$ and $\mathrm{Au}+\mathrm{Ni}$ (PANI/Pt or PEDOT/Pt) by electronic impact. After the functionalization of the sputtered gold external surface using the chemistry of thiol monolayers and the subsequent covalent immobilization of different receptors (antibodies, oligonucleotides and lectins), the resulting microtubes allowed direct optical biosensing of large target biomolecules, such as cancer cells [78] and bacteria [79], as well as indirect biosensing of smaller molecules (DNA [80], proteins [81] and hormones [84]) using different fluorescent labeling strategies.

Regarding direct detection, Janus tubular micromotors manufactured by photolithography and functionalized with a specific antibody were successfully used for the rapid and selective detection of pancreatic cancer cells that overexpressed the carcinoembryonic antigen (CEA) on their surface, in 1:4 diluted human serum (Figure 11b) [78].

Tubular micromotors of much smaller dimensions, manufactured by electroplating PANI/Pt using commercial membranes (Figure 11c) and successive electrodeposition of $\mathrm{Ni}$ and Au layers were applied to the biosensing of pathogenic bacteria. The manufacture of these micromotors is much simpler and cheaper than those prepared by photolithography and allows modulating their dimensions at demand depending on the size of the target biomolecule, enabling the visualization of the recognition process in real-time with no need for a later stage of additional labeling. For this purpose, these microtransporters were modified with the appropriate lectin for the efficient recognition of the target bacteria [79]. Using the affinity reaction of the lectin Concanavalin A by gram-negative bacteria, such as E. coli, it was possible to detect in real-time and at single-cell level this bacterium in drinking water, apple juice and seawater supplemented with the fuel required for the locomotion of the micromotors.

Regarding the indirect biosensing of small molecules, photolitographically prepared $\mathrm{Pt} / \mathrm{Au} / \mathrm{Ni} / \mathrm{Ti}$ microtubes functionalized with a specific thiolated DNA probe were used for the determination of a 30-mer synthetic target DNA at the nanomolar level directly in biological matrices, such as serum, urine, saliva or longer target E. coli $16 \mathrm{~S}$ rRNA in raw bacterial lysates without the need to apply previous pre-treatment or washing steps [80]. Pt/Au/Ni/Ti microtubes functionalized with aptamers were employed for sensitive and selective biosensing of circulating proteins (human thrombin) in biological fluids (serum and plasma) [81]. In both strategies, sandwich formats and fluorescent detection by labeling the biotinylated detector receptors (DNA or aptamer detector probes) with commercial fluorescent nanoparticles modified with streptavidin, were used.

More recently, Au-sputtered PEDOT/Ni/Pt microtubes were modified with a specific antibody and used, in connection with a direct competitive immunoassay using cortisol conjugated with horseradish peroxidase (HRP) and the 3,3',5,5'-tetramethylbencidine (TMB)/ $\mathrm{H}_{2} \mathrm{O}_{2}$ system, to develop and fast naked-eye biosensing strategy enabling "on the move" specific detection of cortisol down to $0.1 \mu \mathrm{g} \mathrm{mL} \mathrm{mL}^{-1}$ in just $2 \mathrm{~min}$ and using microliter sample volumes (Figure 11d) [84].

Self-propelled spherical magnetic Janus particles also exhibit suitability for electrochemical and optical sensing and biosensing. In all cases, propulsion allows these particles to mix with liquids much better than the static ones, which significantly improves the biosensing efficiency. The applications include gold and magnesium micromotors, which operate thanks to corrosion reactions that generate bubbles on one side and propel the engine in the opposite direction. These Janus particles have demonstrated their ability to sense and degrade toxic pesticides or emerging contaminants in complex samples using simple and rapid protocols. 
The remarkable capabilities offered by self-propelled spherical magnetic Janus particles in electrochemical sensing were shown by Wang's group [76]. Water-propelled Mg microparticles with a Ni-Au bilayer patch for magnetic guidance [85], exerted a dual function as "autonomous stirrers" significantly enhancing mass transport and as "natural enzyme mimics", inducing localized pH gradients for non-electroactive analytes degradation. These interesting features hold great promise for electrochemical measurements in microvolume samples at screen-printed electrodes [71,76]. In a pioneering approach, water-driven magnetic $\mathrm{Au}-\mathrm{Ni}-\mathrm{Mg}$ Janus particles were magnetically confined onto the surface of printable sensor strips through the intermediate Ni layer [76]. The particles served as artificial enzymes toward the alkaline and selective hydrolysis of the non-electrochemically detectable pesticide paraoxon into p-nitrophenol, an electroactive and non-hazardous compound (Figure 12a). The method exhibited 15-fold times higher sensitivity towards target analyte detection in the presence of the propelled particles, which was attributed to the enhanced mixing induced by the motion of self-propelled Janus magnetic particles.

a)

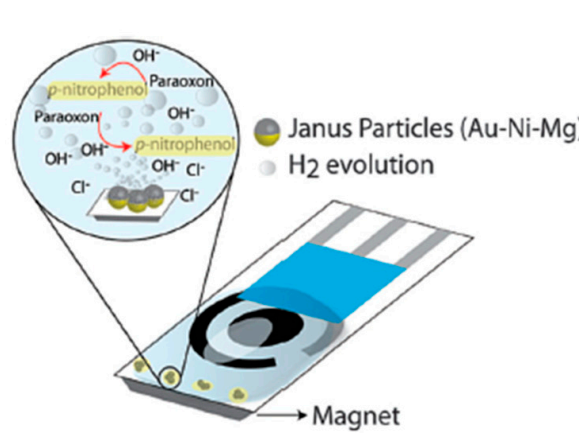

b)

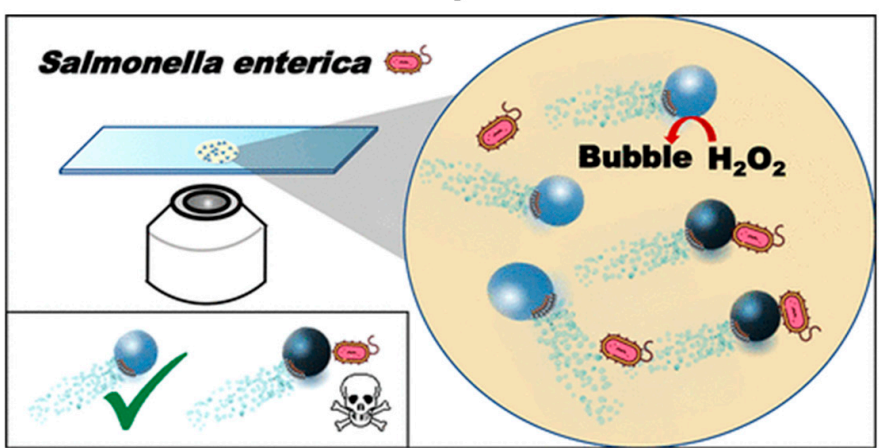

Figure 12. Electrochemical (a) and optical (b) biosensing using self-propelled spherical magnetic Janus particles. Electrochemical detection of organophosphorous nerve agents through their hydrolysis to non-hazardous, but electrochemically detectable by-product (p-nitrophenol) at screen-printed electrodes (a); optical biosensing of enterobacterial contamination by rapid quenching of the native fluorescence of the PABA-functionalized magnetocatalytic hybrid Janus spherical particles upon interaction with the target LPS from Salmonella enterica (b). Reprinted and adapted from (a) [76] and (b) [83] with permission.

Regarding optical sensing, Escarpa's group has used Janus magnetic motors for ultra-fast and sensitive biosensing of highly toxic species, such as deadly bacteria endotoxins [82,83]. The methods involve the use of highly efficient magnetocatalytic hybrid Janus spherical particles, synthesized using an oil-in-water emulsion containing graphene quantum dots (GQDs), PtNPs and $\mathrm{Fe}_{3} \mathrm{O}_{4} \mathrm{NPs}$ and modified with phenylboronic acid (PABA), to detect endotoxins released from E. coli [82] and Salmonella enterica [83] bacteria. The analytical readout relied on the fluorescence quenching upon the interaction of GQDs with the target bacterial lipopolysaccharides (Figure 12b). Due to their two active differentiated regions, these Janus particles can be propelled efficiently both in the presence of $\mathrm{H}_{2} \mathrm{O}_{2}$ and under a magnetic field. Authors reported that these particles can detect selectively the bacterial toxins at a $0.07 \mathrm{ng} \mathrm{mL}^{-1}$ endotoxin concentration, far below the $275 \mu \mathrm{g} \mathrm{mL} \mathrm{m}^{-1}$ level considered toxic to humans [83], in spiked clinical (urine and human serum) and food (milk, mayo, egg yolk and egg white) samples in just 15 min compared with the several hours required by the existing gold standard methods.

\section{Conclusions, Main Challenges to Solve and Future Perspectives}

The relevant progress in the design, fabrication and applications of magnetic Janus particles are reviewed in this article. Details on their synthesis procedures and on (bio)sensing applications of both static and self-propelled systems are highlighted and discussed. 
A unique advantage of magnetic Janus particles is their easy manipulation, also together with their cargo (cells, bacteria, drugs and other biological material) through the application of external magnetic fields which, in turn, avoids the need of using chemical propellants with short lifetimes. In addition, this kind of Janus particles are also prone for functionalization and stand out for their high biocompatibility allowing their use as labels for biosensing, which also results in advantages connected with sensitivity and time of analysis. Moreover, they exhibit intrinsic peroxidase-like catalytic activity useful for such purpose. Furthermore, their anisotropy in shape, composition and surface chemistry allows for the combination of diverse, but complementary analytical functions in a single particle, which is difficult in non-Janus micro and nanoparticles. Moreover, their magnetic property may allow the plain use of magnetic-field based separation and recycling of these particles.

Static magnetic Janus nanoparticles have found application in the simultaneous determination of molecules of biological importance, such as glucose and cholesterol in serum, or multi-detection of DNA and proteins. In addition, they have been used for the effective separation and pre-concentration of biomaterials, thus, meaning an alternative to the usually employed affinity chromatography. Moreover, they have been applied in the integration of bacterial capture, separation and elimination in a single system and, what is more, they can also be used as imaging agents and in drug delivery allowing specific targeting with no damage to healthy cells. In this last field, a single system, including multimodal imaging, targeted drug delivery and cancer imaging-guided therapy has been proposed.

Self-propelled Janus magnetic particles have been used for optical and electrochemical biosensing of clinically relevant analytes, such as nucleic acids, proteins, cancer and bacterial cells, etc. Their autonomous movement has, in fact, allowed the development of efficient and quick biosensing systems able to recognize the target analytes in complex biological samples with no need for sample pretreatment or washing steps. What is more, these particles with free movement around the sample raise the probability of target-receptor contacts, which greatly increases the kinetics and sensitivity of the biosensing events.

Nevertheless, there are major challenges to be confronted before these particles can be introduced, for example, in routine medical care. On the one hand, it is necessary to find a way to easily fabricate at large scale environmentally friendly and low-cost biofunctionalized particle labels with high stability and adequate long-term storage. Quite a number of Janus particles synthetic methods have been reported to date. However, this is still a major challenge to be solved, indeed being one of the main facts hindering the wide applicability of these particles in many fields. Procedures to synthesize magnetic Janus particles are all but simple. Moreover, the synthesis of nano-sized Janus particles is even more complicated, requiring complex chemicals and resulting in the production of low amounts of particles, which is a burden for applications requiring high quantities of this material. For sure, an improvement in the control and yield of synthetic methods together with the preparation of modified JNPs with new capabilities should result in an increase of their potential applicability, thus, helping to introduce them in new practical applications and real-world systems. In fact, modern technologies, such as direct laser writing (DLW) and 3D printing in combination with experimental prototype simulations will allow manufacturing of improved complex architectures which is envisaged as a solution to solve problems associated with the synthesis of magnetic Janus particles.

Also, a more thorough study on the interactions between magnetic Janus particles and biological systems is necessary to allow the prediction of the biological response of multi-functional JNPs which would, in turn, result in more rational designs of these particles as (bio)sensing tools.

Another main challenge relies on the design of point-of-care (POC) devices using magnetic Janus particles, which would be of great interest mostly if they are fitted to the multiplexed analysis of several biomarkers for a single sample. Neither should be forgotten that collaboration among research laboratories and medical centers is highly needed to test the newly developed methodologies by full-scale clinical trials and to actually demonstrate the advantages they can provide as opposed to traditional sensing systems. 
Author Contributions: Writing—review and editing, S.C., M.G., V.S., M.P., P.Y.-S. and J.M.P.; funding acquisition, S.C., P.Y.-S. and J.M.P.

Funding: This research was funded by Spanish Ministerio de Economía y Competitividad, research project CTQ2015-64402-C2-1-R; Ministerio de Ciencia, Innovación y Universidades, research project RTI2018-096135-B-I00; Comunidad de Madrid TRANSNANOAVANSENS-CM Program, Grant P2018/NMT-4349.

Acknowledgments: The financial support of the CTQ2015-64402-C2-1-R (Spanish Ministerio de Economía y Competitividad) and RTI2018-096135-B-I00 (Ministerio de Ciencia, Innovación y Universidades) Research Projects and the TRANSNANOAVANSENS-CM Program from the Comunidad de Madrid (Grant P2018/NMT-4349) are gratefully acknowledged.

Conflicts of Interest: The authors declare no conflict of interest. The funders had no role in the design of the study; in the collection, analyses, or interpretation of data; in the writing of the manuscript, or in the decision to publish the results.

\section{References}

1. Casagrande, C.; Fabre, P.; Raphaël, E.; Veyssie, M. “Janus Beads”: Realization and Behaviour at Water/Oil Interfaces. Europhys. Lett. 1989, 9, 251-255. [CrossRef]

2. De Gennes, P.G. Soft matter. Rev. Mod. Phys. 1992, 64, 645-648. [CrossRef]

3. Shao, Z.; Cao, H.; Yang, Y.; Chen, X. Intelligent Janus nanoparticles for intracellular real-time monitoring of dual drug release. Nanoscale 2016, 8, 6754-6760.

4. Yánez-Sedeño, P.; Campuzano, S.; Pingarrón, J.M. Janus particles for (bio)sensing. Appl. Mat. Today 2017, 9 , 276-288. [CrossRef]

5. Jung, C.W.; Jalani, G.; Ko, J.; Choo, J.; Lim, D.W. Synthesis, characterization, and directional binding of anisotropic biohybrid microparticles for multiplexed biosensing. Macromol. Rapid Commun. 2014, 35, 56-65. [CrossRef] [PubMed]

6. Li, B.; Wang, M.; Chen, K.; Cheng, Z.; Chen, G.; Zhang, Z. Synthesis of Biofunctional Janus Particles. Macromol. Rapid Commun. 2015, 36, 1200-1204. [CrossRef] [PubMed]

7. Yi, Y.; Sanchez, L.; Gao, Y.; Yu, Y. Janus Particles for Biological Imaging and Sensing. Analyst 2016, 141, 3526-3539. [CrossRef] [PubMed]

8. Campuzano, S.; Esteban-Fernández de Ávila, B.; Yáñez-Sedeño, P.; Pingarrón, J.M.; Wang, J. Nano/microvehicles for efficient delivery and (bio)sensing at the cellular level. Chem. Sci. 2017, 8, 6750-6763. [CrossRef]

9. Cohn, D.; Sloutski, A.; Elyashiv, A.; Varma, V.B.; Ramanujan, R. In Situ Generated Medical Devices. Adv. Health Mater. 2019, 8, e1801066.

10. Chen, X.-Z.; Hoop, M.; Mushtaq, F.; Siringil, E.; Hu, C.; Nelson, B.J.; Pané, S. Recent developments in magnetically driven micro- and nanorobots. Appl. Mater. Today 2017, 9, 37-48. [CrossRef]

11. Wang, J. Self-propelled affinity biosensors: Moving the receptor around the sample. Biosens. Bioelectron. 2016, 76, 234-242. [CrossRef] [PubMed]

12. Schrittwieser, S.; Pelaz, B.; Parak, W.J.; Lentijo-Mozo, S.; Soulantica, K.; Dieckhoff, J.; Ludwig, F.; Guenther, A.; Tschöpe, A.; Schotter, J. Homogeneous Biosensing Based on Magnetic Particle Labels. Sensors 2016, 16, 828. [CrossRef] [PubMed]

13. Li, J.; De Ávila, B.E.-F.; Gao, W.; Zhang, L.; Wang, J. Micro/nanorobots for biomedicine: Delivery, surgery, sensing, and detoxification. Sci. Robot. 2017, 2, eaam6431. [CrossRef]

14. Gao, W.; de Ávila, B.E.; Zhang, J.; Wang, J. Targeting and isolation of cancer cells using micro/nanomotors. Adv. Drug Deliv. Rev. 2018, 125, 94-101. [CrossRef]

15. Jurado-Sánchez, B. Nanoscale Biosensors Based on Self-Propelled Objects. Biosensors 2018, 8, 59. [CrossRef]

16. Walther, A.; Müller, A.H.E. Janus Particles: Synthesis, Self-Assembly, Physical Properties, and Applications. Chem. Rev. 2013, 113, 5194-5261. [CrossRef]

17. Brugarolas, T.; Tu, F.; Lee, D. Directed assembly of particles using microfluidic droplets and bubbles. Soft Matter 2013, 9, 9046-9058. [CrossRef]

18. Zhang, L.; Zhang, F.; Dong, W.-F.; Song, J.-F.; Huo, Q.-S.; Sun, H.-B. Magnetic-mesoporous Janus nanoparticles. Chem. Commun. 2011, 47, 1225-1227. [CrossRef] [PubMed]

19. Ning, Y.; Wang, C.; Ngai, T.; Yang, Y.; Tong, Z. Hollow magnetic Janus microspheres templated from double Pickering emulsions. RSC Adv. 2012, 2, 5510-5512. [CrossRef] 
20. Yang, S.; Guo, F.; Kiraly, B.; Mao, X.; Lu, M.; Leong, K.W.; Huang, T.J. Microfluidic synthesis of multifunctional Janus particles for biomedical applications. Lab Chip 2012, 12, 2097-2102. [CrossRef]

21. Kim, J.H.; Jeon, T.Y.; Choi, T.M.; Shim, T.S.; Kim, S.-H.; Yang, S.-M. Droplet microfluidics for producing functional microparticles. Langmuir 2014, 30, 1473-1488. [CrossRef]

22. Varma, V.B. Development of Magnetic Structures by Micro-Magnetofluidic Techniques. Ph.D. Thesis, Nanyang Technological University, Singapore, 2017.

23. Lattuada, M.; Hatton, T.A. Preparation and Controlled Self-Assembly of Janus Magnetic Nanoparticles. J. Am. Chem. Soc. 2007, 129, 12878-12889. [CrossRef]

24. Cai, S.; Luo, B.; Zhan, X.; Zhou, X.; Lan, F.; Yi, Q.; Wu, Y. pH-responsive superstructures prepared via the assembly of $\mathrm{Fe}_{3} \mathrm{O}_{4}$ amphipathic Janus nanoparticles. Regen. Biomater. 2018, 5, 251-259. [CrossRef] [PubMed]

25. Kwak, Y.; Matyjaszewski, K. ARGET ATRP of methyl methacrylate in the presence of nitrogen-based ligands as reducing agents. Polym. Int. 2009, 58, 242-247. [CrossRef]

26. Shaghaghi, B.; Khoee, S.; Bonakdar, S. Preparation of multifunctional Janus nanoparticles on the basis of SPIONs as targeted drug delivery system. Int. J. Pharm. 2019, 559, 1-12. [CrossRef]

27. Li, Y.; Yang, S.; Lu, X.; Duan, W.; Moriga, T. Synthesis and evaluation of the SERS effect of $\mathrm{Fe}_{3} \mathrm{O}_{4}-\mathrm{Ag} \mathrm{Janus}$ composite materials for separable, highly sensitive substrates. RSC Adv. 2019, 9, 2877-2884. [CrossRef]

28. Song, J.; Wu, B.; Zhou, Z.; Zhu, G.; Liu, Y.; Yang, Z.; Lin, L.; Yu, G.; Zhang, F.; Zhang, G.; et al. Double-Layered Plasmonic-Magnetic Vesicles by Self-Assembly of Janus Amphiphilic Gold-Iron(II,III) Oxide Nanoparticles. Angew. Chem. 2017, 129, 8222-8226. [CrossRef]

29. Jishkariani, D.; Wu, Y.; Wang, D.; Liu, Y.; Van Blaaderen, A.; Murray, C.B. Preparation and Self-Assembly of Dendronized Janus $\mathrm{Fe}_{3} \mathrm{O}_{4}-\mathrm{Pt}$ and $\mathrm{Fe}_{3} \mathrm{O}_{4}-\mathrm{Au}$ Heterodimers. ACS Nano 2017, 11, 7958-7966. [CrossRef]

30. Parmar, J.; Vilela, D.; Villa, K.; Wang, J.; Sanchez, S. Micro- and Nanomotors as Active Environmental Microcleaners and Sensors. J. Am. Chem. Soc. 2018, 140, 9317-9331. [CrossRef] [PubMed]

31. Li, T.; Li, J.; Zhang, H.; Chang, X.; Song, W.; Hu, Y.; Shao, G.; Sandraz, E.; Zhang, G.; Li, L.; et al. Magnetically Propelled Fish-Like Nanoswimmers. Small 2016, 12, 6098-6105. [CrossRef]

32. Peng, X.; Gao, F.; Zhao, J.; Li, J.; Qu, J.; Fan, H.; Qu, J.Y. Self-assembly of a graphene oxide $/ \mathrm{MnFe}_{2} \mathrm{O}_{4}$ motor by coupling shear force with capillarity for removal of toxic heavy metals. J. Mater. Chem. A 2018, 6, 20861-20868. [CrossRef]

33. Hwang, J.; Yang, H.-M.; Lee, K.-W.; Jung, Y.-I.; Lee, K.J.; Park, C.W. A remotely steerable Janus micromotor adsorbent for the active remediation of Cs-contaminated water. J. Hazard. Mater. 2019, 369, 416-422. [CrossRef] [PubMed]

34. Indalkar, Y.R.; Gaikwada, S.S.; Ubale, A.T. Janus particles recent and novel approach in drug delivery: An overview. Curr. Pharma Res. 2013, 3, 1031-1037.

35. Wu, Z.; Li, L.; Liao, T.; Chen, X.; Jiang, W.; Luo, W.; Yang, J.; Sun, Z. Janus nanoarchitectures: From structural design to catalytic applications. Nano Today 2018, 22, 62-82. [CrossRef]

36. Zhang, Y.; Huang, K.; Lin, J.; Huang, P.; Zhang, Y. Janus nanoparticles in cancer diagnosis, therapy and theranostics. Biomater. Sci. 2019, 7, 1262-1275. [CrossRef] [PubMed]

37. Tran, L.-T.-C.; Lesieur, S.; Faivre, V. Janus nanoparticles: Materials, preparation and recent advances in drug delivery. Expert Opin. Drug Deliv. 2014, 11, 1061-1074. [CrossRef] [PubMed]

38. Teo, B.M.; Young, D.J.; Loh, X.J. Magnetic anisotropic particles: Toward remotely actuated applications. Part. Part. Syst. Charact. 2016, 33, 709-728. [CrossRef]

39. Li, P.; Niu, X.; Fan, Y. Electrospraying magnetic-fluorescent bifunctional Janus PLGA microspheres with dual rare earth ions fluorescent-labeling drugs. RSC Adv. 2016, 6, 99034-99043. [CrossRef]

40. Li, K.; Li, P.; Jia, Z.; Qi, B.; Xu, J.; Kang, D.; Liu, M.; Fan, Y. Enhanced fluorescent intensity of magnetic-fluorescent bifunctional PLGA microspheres based on Janus electrospraying for bioapplication. Sci. Rep. 2018, 8, 17117. [CrossRef] [PubMed]

41. Lu, C.; Liu, X.; Li, Y.; Yu, F.; Tang, L.; Hu, Y.; Ying, Y. Multifunctional Janus Hematite-Silica Nanoparticles: Mimicking Peroxidase-Like Activity and Sensitive Colorimetric Detection of Glucose. ACS Appl. Mater. Interfaces 2015, 7, 15395-15402. [CrossRef] [PubMed]

42. Sun, X.-T.; Zhang, Y.; Zheng, D.-H.; Yue, S.; Yang, C.-G.; Xu, Z.-R. Multitarget sensing of glucose and cholesterol based on Janus hydrogel microparticles. Biosens. Bioelectron. 2017, 92, 81-86. [CrossRef] [PubMed] 
43. Yuet, K.P.; Hwang, D.K.; Haghgooie, R.; Doyle, P.S. Multifunctional Superparamagnetic Janus Particles. Langmuir 2010, 26, 4281-4287. [CrossRef] [PubMed]

44. Lee, J.; Bisso, P.W.; Srinivas, R.L.; Kim, J.J.; Swiston, A.J.; Doyle, P.S. Universal process-inert encoding architecture for polymer microparticles. Nat. Mater. 2010, 13, 524-529. [CrossRef] [PubMed]

45. Varma, V.B.; Wu, R.G.; Wang, Z.P.; Ramanujan, R.V. Magnetic Janus particles synthesized by droplet micro-magnetofluidic techniques for protein detection. Lab Chip 2017, 17, 3514-3525. [CrossRef] [PubMed]

46. Zhao, P.; George, J.; Li, B.; Amini, N.; Paluh, J.; Wang, J. Clickable Multifunctional Dumbbell Particles for in Situ Multiplex Single-Cell Cytokine Detection. ACS Appl. Mater. Interfaces 2017, 9, 32482-32488. [CrossRef] [PubMed]

47. Appleyard, D.C.; Chapin, S.C.; Srinivas, R.L.; Doyle, P.S. Bar-coded hydrogel microparticles for protein detection: Synthesis, assay and scanning. Nat. Protoc. 2011, 6, 1761-1774. [CrossRef]

48. Zhang, L.; Luo, Q.; Zhang, F.; Zhang, D.-M.; Wang, Y.-S.; Sun, Y.-L.; Dong, W.-F.; Liu, J.-Q.; Huo, Q.-S.; Sun, H.-B. High-performance magnetic antimicrobial Janus nanorods decorated with Ag nanoparticles. J. Mater. Chem. 2012, 22, 23741-23744. [CrossRef]

49. Chang, Z.; Wang, Z.; Lu, M.; Li, M.; Li, L.; Zhang, Y.; Shao, D.; Dong, W. Magnetic Janus nanorods for efficient capture, separation and elimination of bacteria. RSC Adv. 2017, 7, 3550-3553. [CrossRef]

50. Lee, K.-B.; Park, S.; Mirkin, C.A. Multicomponent Magnetic Nanorods for Biomolecular Separations. Angew. Chem. 2004, 116, 3110-3112. [CrossRef]

51. Oh, B.-K.; Park, S.; Millstone, J.E.; Lee, S.W.; Lee, K.-B.; Mirkin, C.A. Separation of Tri-Component Protein Mixtures with Triblock Nanorods. J. Am. Chem. Soc. 2006, 128, 11825-11829. [CrossRef]

52. Chang, Z.-M.; Wang, Z.; Shao, D.; Yue, J.; Lü, M.-M.; Li, L.; Ge, M.; Yang, D.; Li, M.-Q.; Yan, H.; et al. Fluorescent-magnetic Janus nanorods for selective capture and rapid identification of foodborne bacteria. Sens. Actuators B Chem. 2018, 260, 1004-1011. [CrossRef]

53. Pu, L.; Xu, J.; Sun, Y.; Fang, Z.; Chan-Park, M.B.; Duan, H. Cationic polycarbonate-grafted superparamagnetic nanoparticles with synergistic dual-modality antimicrobial activity. Biomater. Sci. 2016, 4, 871-879. [CrossRef] [PubMed]

54. Hao, N.; Chen, X.; Jayawardana, K.W.; Wu, B.; Sundhoro, M.; Yan, M. Shape Control of Mesoporous Silica Nanomaterials Templated with Dual Cationic Surfactants and Their Antibacterial Activities. Biomater. Sci. 2016, 4, 87-91. [CrossRef]

55. Choi, J.-S.; Jun, Y.-W.; Yeon, S.-I.; Kim, H.C.; Shin, J.-S.; Cheon, J. Biocompatible Heterostructured Nanoparticles for Multimodal Biological Detection. J. Am. Chem. Soc. 2006, 128, 15982-15983. [CrossRef]

56. Zijlstra, P.; Orrit, M. Single metal nanoparticles: Optical detection, spectroscopy and applications. Rep. Prog. Phys. 2001, 74, 106401-106456. [CrossRef]

57. Selvan, S.T.; Patra, P.K.; Ang, C.Y.; Ying, J.Y. Synthesis of Silica-Coated Semiconductor and Magnetic Quantum Dots and Their Use in the Imaging of Live Cells. Angew. Chem. Int. Ed. 2007, 46, 2448-2452. [CrossRef]

58. Xu, C.; Ho, D.; Xie, J.; Wang, C.; Kohler, N.; Walsh, E.G.; Morgan, J.R.; Chin, Y.E.; Sun, S. Au-Fe ${ }_{3} \mathrm{O}_{4}$ Dumbbell Nanoparticles as Dual-Functional Probes. Angew. Chem. Int. Ed. 2008, 47, 173-176. [CrossRef]

59. Sotiriou, G.A.; Hirt, A.M.; Lozach, P.-Y.; Teleki, A.; Krumeich, F.; Pratsinis, S.E. Hybrid, silica-coated, Janus-like plasmonic-magnetic nanoparticles. Chem. Mater. 2011, 23, 1985-1992. [CrossRef]

60. Sánchez, A.; Paredes, K.O.; Ruiz-Cabello, J.; Martinez-Ruiz, P.; Pingarron, J.M.; Villalonga, R.; Filice, M. Hybrid Decorated Core@Shell Janus Nanoparticles as Flexible Platform for Targeted Multimodal Molecular Bioimaging of Cancer. ACS Appl. Mater. Interfaces 2018, 10, 31032-31043. [CrossRef] [PubMed]

61. Tao, G.; Bai, Z.; Chen, Y.; Yao, H.; Wu, M.; Huang, P.; Yu, L.; Zhang, J.; Dai, C.; Zhang, L. Generic synthesis and versatile applications of molecularly organic-inorganic hybrid mesoporous organosilica nanoparticles with asymmetric Janus topologies and structures. Nano Res. 2017, 10, 3790-3810. [CrossRef]

62. Xu, C.; Wang, B.; Sun, S. Dumbbell-Like Au-Fe ${ }_{3} \mathrm{O}_{4}$ Nanoparticles for Target-Specific Platin Delivery. J. Am. Chem. Soc. 2009, 131, 4216-4217. [CrossRef] [PubMed]

63. Hu, S.-H.; Chen, S.-Y.; Gao, X. Multifunctional Nanocapsules for Simultaneous Encapsulation of Hydrophilic and Hydrophobic Compounds and On-Demand Release. ACS Nano 2012, 6, 2558-2565. [CrossRef] [PubMed]

64. Wang, F.; Pauletti, G.M.; Wang, J.; Zhang, J.; Ewing, R.C.; Wang, Y.; Shi, D. Dual Surface-Functionalized Janus Nanocomposites of Polystyrene/ $\mathrm{Fe}_{3} \mathrm{O}_{4} @ \mathrm{SiO}_{2}$ for Simultaneous Tumor Cell Targeting and Stimulus-Induced Drug Release. Adv. Mater. 2013, 25, 3485-3489. [CrossRef] 
65. Kilinc, D.; Lesniak, A.; Rashdan, S.A.; Gandhi, D.; Blasiak, A.; Fannin, P.C.; Von Kriegsheim, A.; Kolch, W.; Lee, G.U. Mechanochemical Stimulation of MCF7 Cells with Rod-Shaped Fe-Au Janus Particles Induces Cell Death Through Paradoxical Hyperactivation of ERK. Adv. Health Mater. 2014, 4, 395-404. [CrossRef] [PubMed]

66. Zhang, Q.; Zhang, L.; Li, S.; Chen, X.; Zhang, M.; Wang, T.; Li, L.; Wang, C. Designed Synthesis of $\mathrm{Au} / \mathrm{Fe}_{3} \mathrm{O}_{4}$ @C Janus Nanoparticles for Dual-Modal Imaging and Actively Targeted Chemo-Photothermal Synergistic Therapy of Cancer Cells. Chem. Eur. J. 2017, 23, 17242-17248. [CrossRef] [PubMed]

67. Wu, Q.; Lin, Y.; Wo, F.; Yuan, Y.; Ouyang, Q.; Song, J.; Qu, J.; Yong, K.-T. Novel Magnetic-Luminescent Janus Nanoparticles for Cell Labeling and Tumor Photothermal Therapy. Small 2017, 13, 1701129. [CrossRef] [PubMed]

68. Ju, Y.; Zhang, H.; Yu, J.; Tong, S.; Tian, N.; Wang, Z.; Wang, X.; Su, X.; Chu, X.; Lin, J.; et al. An attractive multifunctional material for triple-modal imaging-guided tumor photothermal therapy. ACS Nano 2017, 11, 9239-9248. [CrossRef]

69. Ruiz, S.C.; Kagan, D.; Orozco, J.; Wang, J. Motion-driven sensing and biosensing using electrochemically propelled nanomotors. Analyst 2011, 136, 4621-4630.

70. Jurado-Sanchez, B.; Escarpa, A. Milli, micro and nanomotors: Novel analytical tools for real-world applications. TrAC Trends Anal. Chem. 2016, 84, 48-59. [CrossRef]

71. Jurado-Sánchez, B.; Escarpa, A. Janus micromotors for electrochemical sensing and biosensing applications: A review. Electroanalysis 2017, 29, 14-23. [CrossRef]

72. Jurado-Sánchez, B.; Pacheco, M.; Maria-Hormigos, R.; Escarpa, A. Perspectives on Janus micromotors: Materials and applications. Appl. Mater. Today 2017, 9, 407-418. [CrossRef]

73. Kong, L.; Guan, J.; Pumera, M. Micro- and nanorobots based sensing and biosensing. Curr. Opin. Electrochem. 2018, 10, 174-182. [CrossRef]

74. Kagan, D.; Calvo-Marzal, P.; Balasubramanian, S.; Sattayasamitsathit, S.; Manesh, K.M.; Flechsig, G.-U.; Wang, J. Chemical sensing based on catalytic nanomotors: Motion-based detection of trace silver. J. Am. Chem. Soc. 2009, 131, 12082-12083. [CrossRef] [PubMed]

75. Wu, J.; Balasubramanian, S.; Kagan, D.; Manesh, K.M.; Campuzano, S.; Wang, J. Motion-based DNA detection using catalytic nanomotors. Nat. Commun. 2010, 1, 36. [CrossRef] [PubMed]

76. Valdés-Ramírez, G.; Cinti, S.; Gao, W.; Li, J.; Palleschi, G.; Wang, J. Microengine-assisted electrochemical measurements at printable sensor strips. Chem. Commun. 2015, 51, 8668-8671.

77. Moo, J.G.S.; Pumera, M. Self-Propelled Micromotors Monitored by Particle-Electrode Impact Voltammetry. ACS Sens. 2016, 1, 949-957. [CrossRef]

78. Balasubramanian, S.; Kagan, D.; Hu, C.-M.J.; Campuzano, S.; Lobo-Castañon, M.J.; Lim, N.; Kang, D.Y.; Zimmerman, M.; Zhang, L.; Wang, J. Micromachine-Enabled Capture and Isolation of Cancer Cells in Complex Media. Angew. Chem. 2011, 123, 4247-4250. [CrossRef]

79. Campuzano, S.; Orozco, J.; Kagan, D.; Guix, M.; Gao, W.; Sattayasamitsathit, S.; Claussen, J.C.; Merkoçi, A.; Wang, J. Bacterial isolation by lectin-modified microengines. Nano Lett. 2012, 12, 396-401. [CrossRef] [PubMed]

80. Kagan, D.; Campuzano, S.; Balasubramanian, S.; Kuralay, F.; Flechsig, G.-U.; Wang, J.; Ruiz, S.C. Functionalized Micromachines for Selective and Rapid Isolation of Nucleic Acid Targets from Complex Samples. Nano Lett. 2011, 11, 2083-2087. [CrossRef]

81. Orozco, J.; Campuzano, S.; Kagan, D.; Zhou, M.; Gao, W.; Wang, J.; Ruiz, S.C. Dynamic Isolation and Unloading of Target Proteins by Aptamer-Modified Microtransporters. Anal. Chem. 2011, 83, 7962-7969. [CrossRef]

82. Jurado-Sánchez, B.; Pacheco, M.; Rojo, J.; Escarpa, A.; Jurado-Sánchez, B.; Jurado-Sánchez, B. Magnetocatalytic Graphene Quantum Dots Janus Micromotors for Bacterial Endotoxin Detection. Angew. Chem. Int. Ed. 2017, 56, 6957-6961. [CrossRef]

83. Pacheco, M.; Escarpa, A.; Sánchez, B.J. Sensitive Monitoring of Enterobacterial Contamination of Food Using Self-Propelled Janus Microsensors. Anal. Chem. 2018, 90, 2912-2917. [CrossRef] [PubMed] 
84. Esteban-Fernández de Ávila, B.; Zhao, M.; Campuzano, S.; Ricci, F.; Pingarrón, J.M.; Mascini, M.; Wang, J. Rapid micromotor-based naked-eye immunoassay. Talanta 2017, 167, 651-657. [CrossRef] [PubMed]

85. Gao, W.; Feng, X.; Pei, A.; Gu, Y.; Li, J.; Wang, J. Seawater-driven magnesium based Janus micromotors for environmental remediation. Nanoscale 2013, 5, 4696-4700. [CrossRef] [PubMed]

(C) 2019 by the authors. Licensee MDPI, Basel, Switzerland. This article is an open access article distributed under the terms and conditions of the Creative Commons Attribution (CC BY) license (http://creativecommons.org/licenses/by/4.0/). 